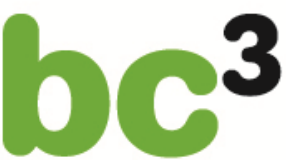

BASQUE CENTRE

FOR CLIMATE CHANGE

Klima Aldaketa Ikergai

\title{
Evaluation of Two Alternative Carbon Capture and Storage Technologies:
}

\section{A Stochastic Model}

Luis M. Abadie, Ibon Galarraga and Dirk Rübbelke

March 2013

LOW CARBON PROGRAMME

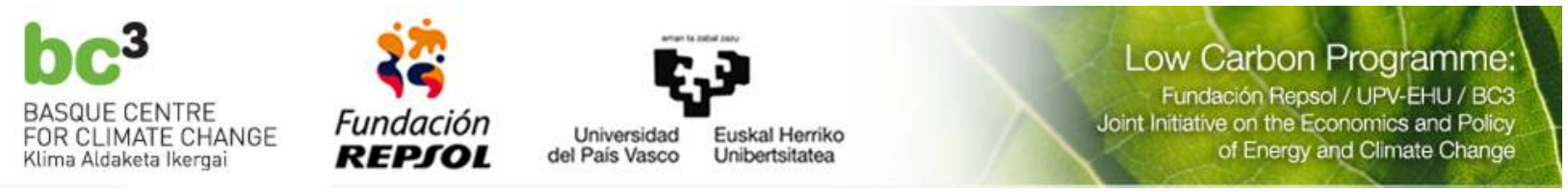

BC3 WORKING PAPER SERIES

2013-07 
The Basque Centre for Climate Change (BC3) is a Research Centre based in the Basque Country, which aims at contributing to long-term research on the causes and consequences of Climate Change in order to foster the creation of knowledge in this multidisciplinary science.

The BC3 promotes a highly-qualified team of researchers with the primary objective of achieving excellence in research, training and dissemination. The Scientific Plan of BC3 is led by the Scientific Director, Prof. Anil Markandya.

The core research avenues are:

- $\quad$ Adaptation to and the impacts of climate change

- $\quad$ Measures to mitigate the amount of climate change experienced

- International Dimensions of Climate Policy

- Developing and supporting research that informs climate policy in the Basque Country

See www.bc3research.org for further details.

This Working paper has been produced under the Low Carbon Programme initiative: http://www.lowcarbonprogramme.org/

The BC3 Working Paper Series is available on the internet at http://www.bc3research.org/working papers/view.html

Enquiries (Regarding the BC3 Working Paper Series):

Prof. Sérgio H. Faria

Email: sergio.faria@bc3research.org

The opinions expressed in this policy briefing are responsibility of the authors and do not necessarily reflect the position of Basque Centre for Climate Change (BC3) nor the sponsors of the Low Carbon Programme (i.e. Fundación Repsol).

Note: If printed, please remember to print on both sides. Also, perhaps try two pages on one side 


\title{
Evaluation of Two Alternative Carbon Capture and Storage Technologies: A Stochastic Model
}

\author{
Luis M. Abadie*, Ibon Galarraga*** and Dirk Rübbelke*,***
}

In this paper we evaluate two alternative CCS technologies of a coal-fired power plant from an investor's point of view. The first technology uses $\mathrm{CO}_{2}$ for enhanced oil recovery (EOR) paired with storage in deep saline formations (DSP) and the second one just stores $\mathrm{CO}_{2}$ in DSF. For projects of this type there are many sources of risk, and three sources of uncertainty stand out: the price of electricity, the price of oil and the price of carbon allowances. In this paper we develop a general stochastic model that can be adapted to other projects such as enhanced gas recovery (EGR) or industrial plants that use $\mathrm{CO}_{2}$ for either EOR or EGR with CCS. The model is calibrated with UK data and applied to help understand the conditions that generate the incentives needed for early investments in these technologies. Additionally, we analyse the risks of these investments

Keywords: carbon capture and storage, enhanced oil recovery, power plants, stochastic model, futures markets, real options.

Cite as: Abadie, L.M., I. Galarraga and D. Rübbelke (2013) Evaluation of two alternative carbon capture and storage technologies: a stochastic model. BC3 Working Paper Series 2013-07. Basque Centre for Climate Change (BC3), Bilbao, Spain

\footnotetext{
"Basque Centre for Climate Change (BC3), Alameda Urquijo 4, 4. 48008, Bilbao (Spain). Tel. +34 94-401 46 90, Fax. +34 94-405 47 87. www.bc3research.org. Corresponding author: 1m.abadie@bc3.research.org

${ }^{* *}$ University of the Basque Country (UPV-EHU). Av. Lehendakari Aguirre, 83, 48015 Bilbao, Spain.

${ }^{* * *}$ Ikerbasque-Basque Foundation for Science, 48011 Bilbao, Spain.
} 


\section{Introduction}

Carbon dioxide capture and storage (CCS) is frequently seen as an effective means of stabilizing the global climate (IPCC, 2005, Luderer et al., 2012, Szulczewski et al., 2012) and as a key technology in the future portfolio of carbon abatement technologies (IEA, 2011). "Achieving substantial reductions in temperatures relative to the coal-based system [...] will depend on rapid and massive deployment of some mix of conservation, wind, solar, and nuclear, and possibly carbon capture and storage" (Myhrvold and Caldeira, 2012: 7-8). Specifically concerning the deployment of CCS in the European Union in the coming decades, de Coninck et al. (2009) point out that "[t]here are no compelling scientific, technical, legal, or economic reasons" against it. CCS could induce $\mathrm{CO}_{2}$ reductions between 5.1 and $10.4 \mathrm{Gt}$ per year in 2050 , that is around $14 \%$ to $19 \%$ of the total $\mathrm{CO}_{2}$ abated globally (IEA, 2007). If the CCS option is not intensively exploited, the cost of a $50 \%$-reduction in emissions by 2050 as suggested by the IPCC (2007) would be $71 \%$ or USD 1.28 trillion higher (IEA, 2007). However, CCS technologies still need to attain a higher degree of maturity before they can play a significant role in the portfolio of mitigation options, and it is broadly expected that CCS will not become commercially available in the power sector before 2020 (Haszeldine 2009). Abadie and Chamorro (2008) analyse the negative effect of uncertainty on CCS investments that could cause a delay in this type of investment. Other pieces of work such as Middleton et al (2012) presents a model to optimise capture, transport and storage of $\mathrm{CO}_{2}$ while another paper by van den Broek et al (2010) develops a toolbox for the design of $\mathrm{CO}_{2}$ infrastructures in the Netherlands.

One CCS strategy offering attractive features is the use of captured carbon in $\mathrm{CO}_{2}$ Enhanced Oil Recovery $\left(\mathrm{CO}_{2}\right.$-EOR). EOR is a method of extracting oil from wells in which traditional techniques are unable of recovering any more quantities. It allows for a significant rise in the total amount of oil extracted and therefore in the profitability of the wells involved. The geological characteristics of depleted oil and gas fields are well known, which makes the use of these wells for carbon storage quite attractive. EOR can help to store carbon captured - inter alia - at coal-fired power plants which is the kind of plant we are focusing on in our analysis. This is especially relevant because in 2050 "coal-based generation is forecast to be $252 \%$ higher than in 2005 , accounting for $52 \%$ of all power generation" (IEA 2008: 31). But carbon emissions captured from, e.g. gas-fired power plants (Tzimas et al., 2005), ${ }^{1}$ biomass use, ${ }^{2}$ and industrial applications can also fuel EOR processes. In a context of high oil prices and decreasing oil extraction in mature basins investment in CCS in combination with EOR might become a profitable strategy.

From an investor's point of view the profitability of a CCS installation in combination with EOR is affected by several factors that are worth mentioning:

a) Costs of CCS in combination with EOR: A significant part of the total costs of $\mathrm{CO}_{2}$-EOR is caused by the electricity needed to compress $\mathrm{CO}_{2}$ and it is therefore very sensitive to electricity price changes and volatility. ${ }^{3}$ The higher the volatility the greater the risk for an investor, and the higher the expected price of electricity the lower the expected profitability of investing in CCS.

\footnotetext{
${ }^{1}$ However, $\mathrm{CO}_{2}$ from gas-fired plants for $\mathrm{CO}_{2}$-EOR is less profitable than that which comes from coal-fired power plants.

${ }^{2}$ We thus disregard the option of combining bioenergy with CCS which would even constitute an option for the removal of carbon emissions from the atmosphere (see, e.g., Azar et al., 2006).

${ }^{3}$ We mean volatility of electricity prices once the deterministic component (i.e. seasonality) and the tendency (including the mean reversion) are eliminated.
} 
b) Carbon emission allowances saved, if the investing company operates within an emission trading scheme. Here again expected prices of allowances and volatility will have an effect.

c) Benefits from the use of $\mathrm{CO}_{2}$ : Carbon dioxide is a productive input in the EOR process. The benefits will be related to the price of (the recovered) oil and its volatility.

d) Benefits derived from support from public authorities such as subsidies, fiscal incentives, loans, etc.

This paper analyses the decision concerning a $\mathrm{CO}_{2}$-EOR investment in the UK, taking into account the three investment criteria a)-c) (price of electricity, cost of allowances and price of oil) which pose a risk to the $\mathrm{CO}_{2}$-EOR project's profitability. Additionally, it uses sensitivity analysis to understand the effects of higher investment costs and different supporting policies such as subsidies and other fiscal incentives. The methodology presented here can be easily adapted to other CCS projects using different technologies (e.g. enhanced gas recovery) and which can be located in other countries. Specifically the model can be adapted for both onshore and offshore investment.

We develop a case study choosing the UK as the location for the CCS/EOR investment for several reasons. The UK has already developed a CCS Roadmap that sets out how commercial deployment of CCS in the UK can be achieved in the 2020s (DECC, 2012). Furthermore, there is abundant carbon storage capacity, which is assessed to be 1.5 times as high as the $\mathrm{CO}_{2}$ emissions from British large point sources in the next 40 years (Höller and Viebahn 2011: 4903). Finally, social acceptance of CCS in general (Shackley et al., 2009) and of EOR/EGR in particular is rather high in the UK. As Shackley et al. (2007) find out in a survey investigating stakeholder opinions regarding the role of CCS in Europe, "82-3\% of respondents in Norway, Denmark and the UK [...] thought that opportunities for EOR/EGR were important or very important for CCS development; $54 \%$ of respondents in the Netherlands [...] also responded in this way, whilst the value for France was $43 \%$ and $32 \%$ for Germany".

From the point of view of a power investor, building coal-fired power plants with CCS or retrofitting existing ones will cause high investment costs which vary with the technology used. Just as an indication, the cost of a plant with carbon capture can be between $50 \%$ and $100 \%$ higher (IEA, 2008: 60) than those of conventional ones. The installation of a CCS unit is generally more profitable for big, efficient plants while retrofitting of an existing power plant is more costly. The use of $\mathrm{CO}_{2}$ in EOR can offset a part of the CCS cost.

There are several barriers to the effective implementation of CCS technology, including financial, political, technical and public acceptability barriers (Johnsson et al., 2010). In fact, currently the number of projects is relatively small and some projects have been cancelled for reasons mentioned above. As of mid-2012 there are eight CCS projects currently up and running, capturing 23.2 million tonnes per annum (Mtpa). Another seven projects are under construction with a total additional capacity of $12.0 \mathrm{Mtpa}$ (Global CSS Institute, 2012). None of the existing projects is connected to power generation plants. Among those under construction, there are 2 for power generation and EOR. Therefore, the type of project that this paper is analysing cannot yet be found operating in the market. The methodology focuses on understanding the main financial obstacles to the implementation of the technology.

We address the conditions under which CCS with EOR might become a profitable business activity, accounting for the three sources of uncertainty mentioned above, considering fixed and variable costs of capture, transport and storage. The sensitivity of business projects towards changes in them is also 
studied. Some of these analyses include construction costs which, of course, may vary over time and across space. Implementing CCS technologies leads to increases in capital costs and operating expenses while decreasing energy efficiency in plants. In terms of cost per tonne, the figure can be as much as USD 40-55 for coal fired plants (IEA, 2008).

A stochastic model of commodity prices is developed that is calibrated with prices (quotes) of futures markets in the UK, with the most appropriate dynamics being selected to represent their behaviour (seasonality and mean reversion or Geometric Brownian Motion). The selection of futures markets is based on the proximity of depleted oil and gas fields in the North Sea.

The results illustrate the influence of stochastic prices (with their expected values, volatility and correlations) when deciding whether or not to construct a plant of this type. The impact of nonstochastic fixed and variable costs is also analysed. The results may contribute to the design of efficient policies to support the construction of plants, striking the right balance between profitability and risk.

Additional to the investigation in investments in CCS with EOR paired with storage in deep saline formations (DSF), we consider an alternative investment option, i.e. investment in CCS using only DSF as sinks for $\mathrm{CO}_{2}$.

Note that the paper assumes that there is coordination among the companies involved in the phases of capture, transport and storage in such a way that they equitably share the total benefits.

The paper is organised as follows: Section 2 develops the stochastic models of commodities and carries out calibrations to obtain parameters. Section 3 studies the costs and benefits of investing in $\mathrm{CO}_{2}$-EOR in the capture, transportation and storage phases. In this and the following sections, these investments are confronted with those in an alternative option, i.e. CCS using only DSF. Section 4 derives the Net Present Value (NPV) when investment can only take place at the outset, while Section 5 analyses the option to invest when there is a 10 -year period in which to make the decision. We perform a sensitivity analysis that will inform the process of designing effective supporting policies for investing in CCS with EOR. The final Section is devoted to conclusions.

\section{Stochastic Model and Data}

\subsection{The Model}

We specify an equation that allows for the long term prices as mean reverting stochastic processes that behave according to the following differential equation system in a risk-neutral world. This specification allows for seasonality and the Geometric Brownian Motion (GBM) as particular cases. The equation is:

$$
\begin{aligned}
d S_{t}^{i} & =d f_{i}(t)+\left[k_{S}^{i}\left(S_{m}^{i}-\left(S_{t}^{i}-f_{i}(t)\right)\right)-\lambda_{S}^{i}\left(S_{t}^{i}-f_{i}(t)\right)\right] d t+\sigma_{S}^{i}\left(S_{t}^{i}-f_{i}(t)\right) d W_{t}^{i} \\
& =d f_{i}(t)+\left[k_{S}^{i} S_{m}^{i}-\left(k_{S}^{i}+\lambda_{S}^{i}\right)\left(S_{t}^{i}-f_{i}(t)\right)\right] d t+\sigma_{S}^{i}\left(S_{t}^{i}-f_{i}(t)\right) d W_{t}^{i}
\end{aligned}
$$

where

$i \in\{E, A, O\}$, with $E=$ Electricity, $A=$ Carbon Allowances and $O=$ Oil. $S_{t}^{i}$ is the price at time $t$ of the commodity $i$. 
$S_{m}^{i}$ is the level to which the deseasonalised price of the commodity $i$ tends in the long run. In the case of carbon allowances a GBM is used so no equilibrium value exists for the long run: $S_{m}^{A}=0$.

$f_{i}(t)$ is a deterministic function that captures the effect of seasonality in the prices of commodity $i$. This function is defined as follows: $f_{i}(t)=\gamma_{i} \cos \left(2 \pi\left(t+\varphi_{i}\right)\right)$, where the time $t$ is measured in years and the angle in radians; when $f\left(t=-\varphi_{i}\right)=\gamma_{i}$ the seasonal maximum value is reached. In our case, $f_{A}(t)=f_{O}(t)=0$, that is, seasonality is only present in the prices (quotations) of electricity.

$\sigma_{S}^{i}$ is the instantaneous volatility of the deseasonalised price, which determines the variance at $t$ of $S_{t}^{i}$.

$\lambda_{S}^{i} S_{t}^{i}$ is the market price of risk for commodity $i$; its use in the differential equation makes it possible to carry out the valuation in the risk-neutral world. $k_{S}^{i}$ is the speed of reversion towards the "normal" level of electricity, natural gas and oil, $k_{S}^{i}+\lambda_{S}^{i}$ can be computed as $k_{S}^{i}+\lambda_{S}^{i}=\ln 2 / t_{1 / 2}^{S^{i}}$, where $t_{1 / 2}^{S^{E}}$ is the expected half-life for deseasonalised electricity, i.e. the time required for the gap between $S_{0}^{E}-f_{E}(0)$ and $S_{m}^{E}$ to halve. For the case of carbon allowances GBM is used so $-\left(k_{S}^{A}+\lambda_{S}^{A}\right)$ is the drift in the risk-neutral word.

The expected value, or equivalently the futures price with maturity $t$, at time $t_{0}$ is

$$
F\left(S_{0}^{i}, t\right)=E^{Q}\left(S_{t}^{i}\right)=f_{i}(t)+\frac{k_{S}^{i} S_{m}^{i}}{k_{S}^{i}+\lambda_{S}^{i}}\left[1-e^{-\left(k_{S}^{i}+\lambda_{S}^{i}\right)\left(t-t_{0}\right)}\right]+\left(S_{0}^{i}-f_{i}\left(t_{0}\right)\right) e^{-\left(k_{S}^{i}+\lambda_{S}^{i}\right)\left(t-t_{0}\right)}
$$

Hence in this case, $F\left(S_{0}^{i}, \infty\right)-f_{i}(\infty)=\frac{k_{S}^{i} S_{m}^{i}}{k_{S}^{i}+\lambda_{S}^{i}}$, and is zero for $i=A$.

\subsubsection{The Data}

The data used are summarised in Table 1.

\begin{tabular}{|l|l|c|}
\hline \multicolumn{2}{|c|}{ Table 1: Markets, products and quotations } \\
\hline \multicolumn{1}{|c|}{ Contract } & \multicolumn{1}{|c|}{ Quotation } & Contract size \\
\hline ICE Brent Crude futures & US dollars and cents per barrel & \\
ICE UK Base Electricity & Sterling and in pounds and pence \\
Futures & per MWh & 1,000 barrels \\
ICE ECX EUA Futures & Euros and cents per metric tonne & per day \\
Bluenext Spot EUA & Euros and cents per metric tonne & $1,000 \mathrm{CO}_{2}$ EU Allowances \\
& $1,000 \mathrm{CO}_{2}$ EU Allowances \\
\hline
\end{tabular}

\footnotetext{
${ }^{4} 1$ barrel $=42$ gallons.
} 
The original prices have been converted to USD using the daily spot exchange rate and the term structure of each currency on the same day, calculating the forward exchange rate.

Figure 1 shows the behaviour of the term structure of futures contracts on electricity. It can be noted that seasonality exists for every day together with a process of mean reversion.

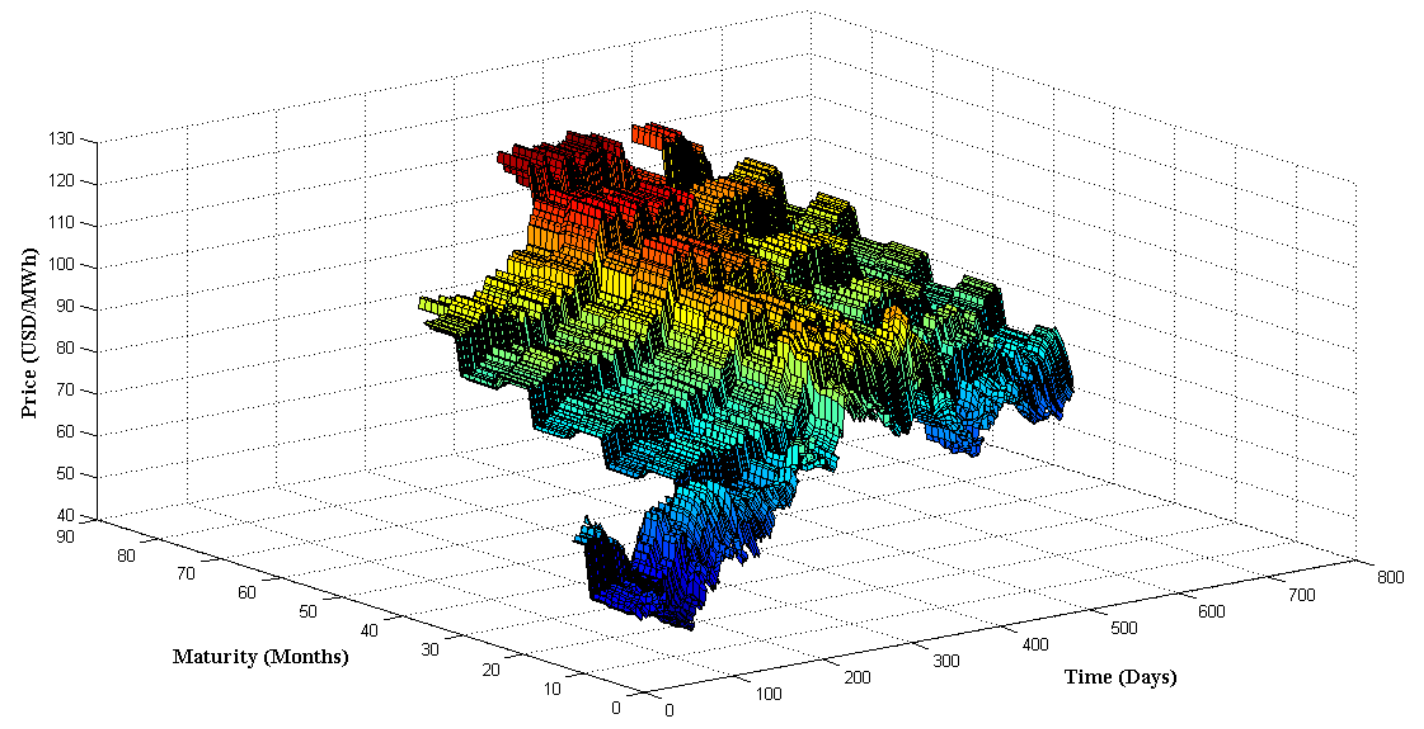

Figure 1: ICE UK Base Electricity Futures

On the other hand (see Figure 2), the prices of oil on the futures market show no seasonality, but they do show a mean-reverting behaviour. The long-run equilibrium price shows some volatility. It can also be added that the term structure of the futures prices for oil incentivize early investment. This is so because, for the oil obtained with EOR, higher prices can be assured for the immediately following months than for longer maturity periods. In addition to this effect, there is the effect of discounting (at the riskless rate).

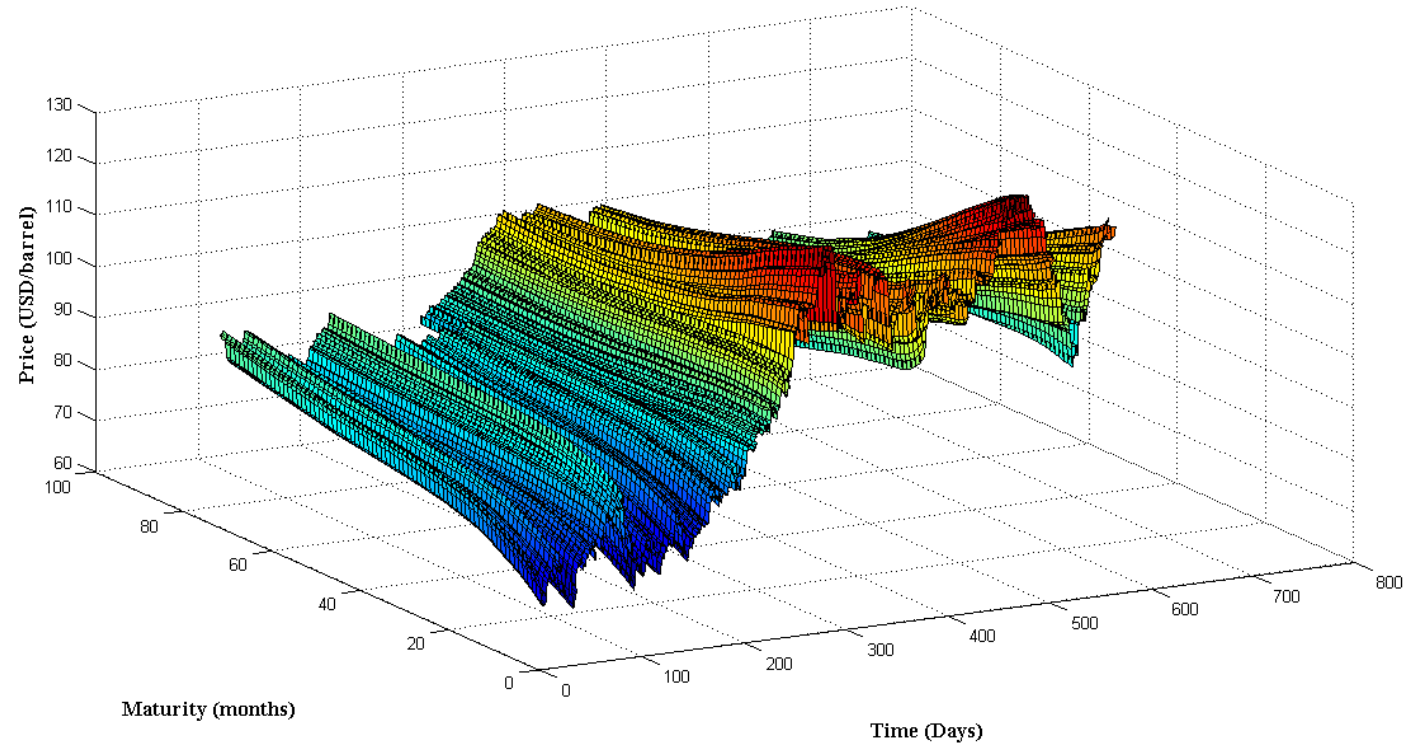

Figure 2: ICE Brent Crude futures 
Finally, Figure 3 indicates that the price of carbon allowances shows no seasonality and no meanreverting behaviour, but does show a stable slope with the initial price being a little volatile but becoming less so as days pass by. Carbon prices are relatively low and thus do not contribute significantly to generating incentives for investing in CCS. However, note that prices for those maturities further away in time are a little higher.

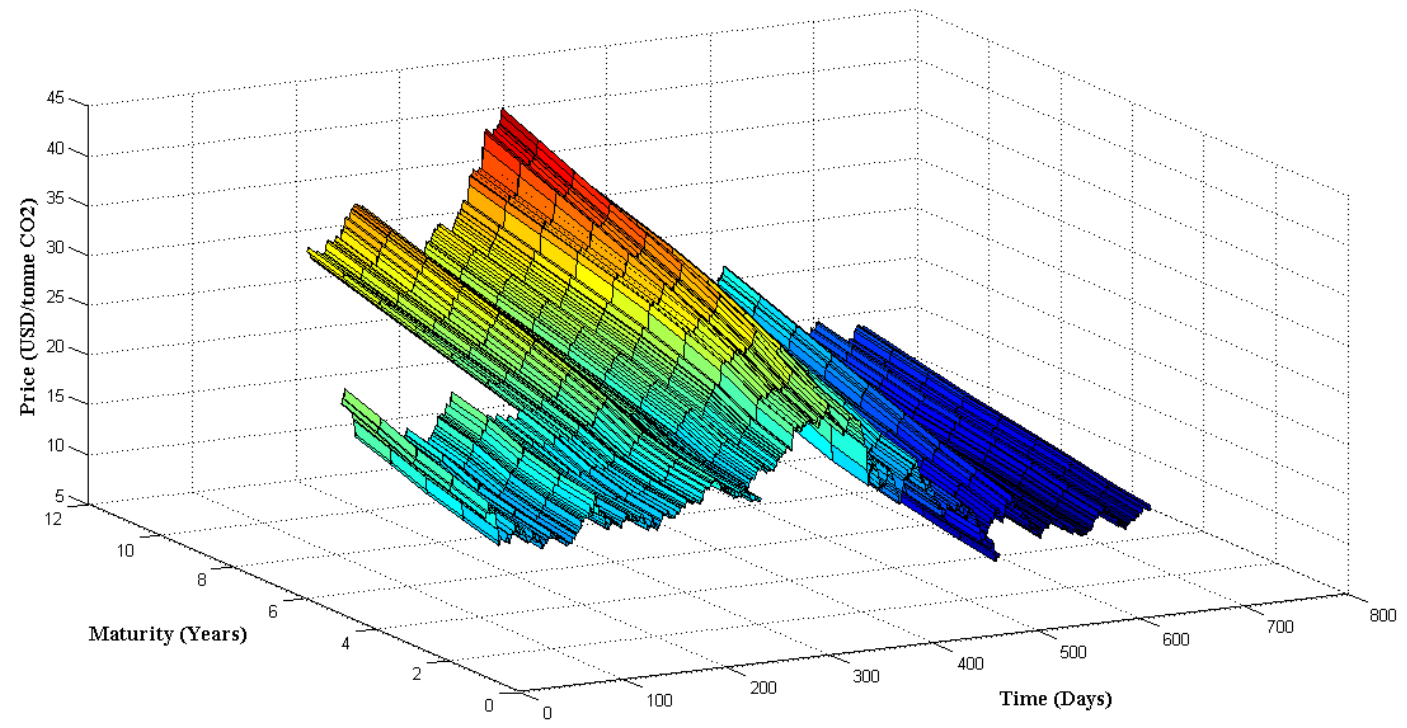

Figure 3: ICE ECX EUA Futures

\subsection{Estimation}

We estimate the parameters in the stochastic model using all the futures prices for each day and nonlinear least-squares. The data available for each of the 713 days from 12/01/2009 to 08/31/2012 consist of 32,250 observations of monthly UK Base Electricity Futures on the Intercontinental Exchange (NYSE: ICE). The electricity prices for future months are assumed to incorporate all available information on cost of generation and profit. The information includes the cost of fuels, $\mathrm{CO}_{2}$ allowances and plans to phase out some plants and set up new ones. Table 2 shows the results for electricity with standard errors while Table 3 shows the results for all commodities.

\begin{tabular}{|c|c|c|c|c|}
\hline \multicolumn{5}{|c|}{ Table 2: Nonlinear least-squares estimation: Electricity } \\
\hline Parameter & Value & std. error & t-ratio & p-value \\
\hline$k_{S}^{E}+\lambda_{S}^{E}$ & 0.0573 & 0.0014 & 41.30 & 0.000 \\
$\frac{k_{S}^{E} S_{m}^{E}}{k_{S}^{E}+\lambda_{S}^{E}}$ & 195.586 & 2.6554 & 73.66 & 0.000 \\
$\gamma_{\mathrm{E}}$ & 4.51656 & 0.0270 & 167.0 & 0.000 \\
$\varphi_{E}$ (years) $)$ & 0.03016 & 0.0010 & 31.55 & 0.000 \\
\hline
\end{tabular}


It can be seen that while electricity shows some seasonality it does not significantly affect long term investments since, on the one hand, changes in prices due to seasonality are not correlated to changes in prices of other stochastic commodities such as oil or carbon. And, on the other hand, we are assuming that once it is decided to invest in CCS the plant will be operated independently of the electricity price. Using CCS when electricity prices are low due to seasonal factors offsets the impacts of periods of high prices. As expected, there is a correlation between the seasonally adjusted price of electricity and the prices of oil and carbon.

\begin{tabular}{|c|c|c|c|}
\hline \multicolumn{3}{|c|}{ Table 3: Nonlinear least-squares estimation } \\
\hline Parameter & Electricity & Oil & Carbon \\
& USD/MWh & USD/barrel & USD/tonne \\
\hline Num Obs. & 32,250 & 49,403 & 6,162 \\
$\frac{k_{S}^{i} S_{m}^{i}}{k_{S}^{i}+\lambda_{S}^{i}}$ & 195.586 & 93.6795 & - \\
$k_{S}^{i}+\lambda_{S}^{i}$ & 0.0573 & 0.3054 & -0.05208 \\
$\gamma_{\mathrm{E}}$ & 4.51656 & - & - \\
$\varphi_{E}($ years $)$ & 0.03016 & - & - \\
$S_{0}^{i}-f_{i}(0)$ & 69.1812 & 115.0470 & 10.065 \\
\hline
\end{tabular}

In the real world $\lambda_{S}^{i}=0$ and:

$$
d S_{t}^{i}=d f_{i}(t)+\left[k_{S}^{i} S_{m}^{i}-k_{S}^{i}\left(S_{t}^{i}-f_{i}(t)\right] d t+\sigma_{S}^{i}\left(S_{t}^{i}-f_{i}(t)\right) d W_{t}^{i}\right.
$$

Therefore, discretising:

$$
\left(S_{t+\Delta t}^{i}-S_{t}^{i}\right)+\left(f_{i}(t+\Delta t)-f_{i}(t)\right)=\left[k_{S}^{i} S_{m}^{i}-k_{S}^{i}\left(S_{t}^{i}-f_{i}(t)\right)\right] \Delta t+\sigma_{S}^{i}\left(S_{t}^{i}-f_{i}(t)\right) \sqrt{\Delta t} \varepsilon_{t}^{i}
$$

and applying seasonally adjusted series:

$$
D_{t}^{i}=S_{t}^{i}-f_{i}(t)
$$

the following difference equation is obtained:

$$
\Delta D_{t}^{i}=\left[k_{S}^{i} S_{m}^{i}-k_{S}^{i} D_{t}^{i}\right] \Delta t+\sigma_{S}^{i} D_{t}^{i} \sqrt{\Delta t} \varepsilon_{t}^{i}
$$

or, alternatively

$$
\frac{D_{t+\Delta t}^{i}-D_{t}^{i}}{D_{t}^{i}}=-k_{S}^{i} \Delta t+k_{S}^{i} \Delta t S_{m}^{i} \frac{1}{D_{t}^{i}}+\sigma_{S}^{i} \sqrt{\Delta t} \varepsilon_{t}^{i}
$$


Volatility can be estimated through a regression model; in the case of Geometric Brownian Motion $(\mathrm{GBM})$ it is:

$$
\frac{D_{t+\Delta t}^{i}-D_{t}^{i}}{D_{t}^{i}}=-k_{S}^{i} \Delta t+\sigma_{S}^{i} \sqrt{\Delta t} \varepsilon_{t}^{i}
$$

Table 4 shows the results for volatility while estimated correlations are shown in Table 5.

\begin{tabular}{|c|c|c|l|}
\hline \multicolumn{4}{|l|}{ Table 4: Volatility estimates } \\
\hline Parameter & Electricity & \multicolumn{1}{l|}{ Oil } & Carbon \\
\hline$\sigma_{i}$ & 0.2578 & 0.2700 & 0.4535 \\
\hline
\end{tabular}

\begin{tabular}{|c|c|c|c|}
\hline \multicolumn{4}{|l|}{ Table 5: Correlations estimates } \\
\hline$\rho_{i, j}$ & Electricity & Oil & Carbon \\
\hline Electricity & 1.0000 & 0.1797 & 0.3851 \\
Oil & 0.1797 & 1.0000 & 0.2644 \\
Carbon & 0.3851 & 0.2644 & 1.0000 \\
\hline
\end{tabular}

Figures 4, 5 and 6 show observed values alongside those constructed with estimated parameters and the initial price on the last day of the series, that is, the $31^{\text {st }}$ of August, 2012. When the whole sample is used to estimate the long term equilibrium price for oil, the price is higher (Figure 5) than the one obtained using only the quotes on the last day (08/31/2012).

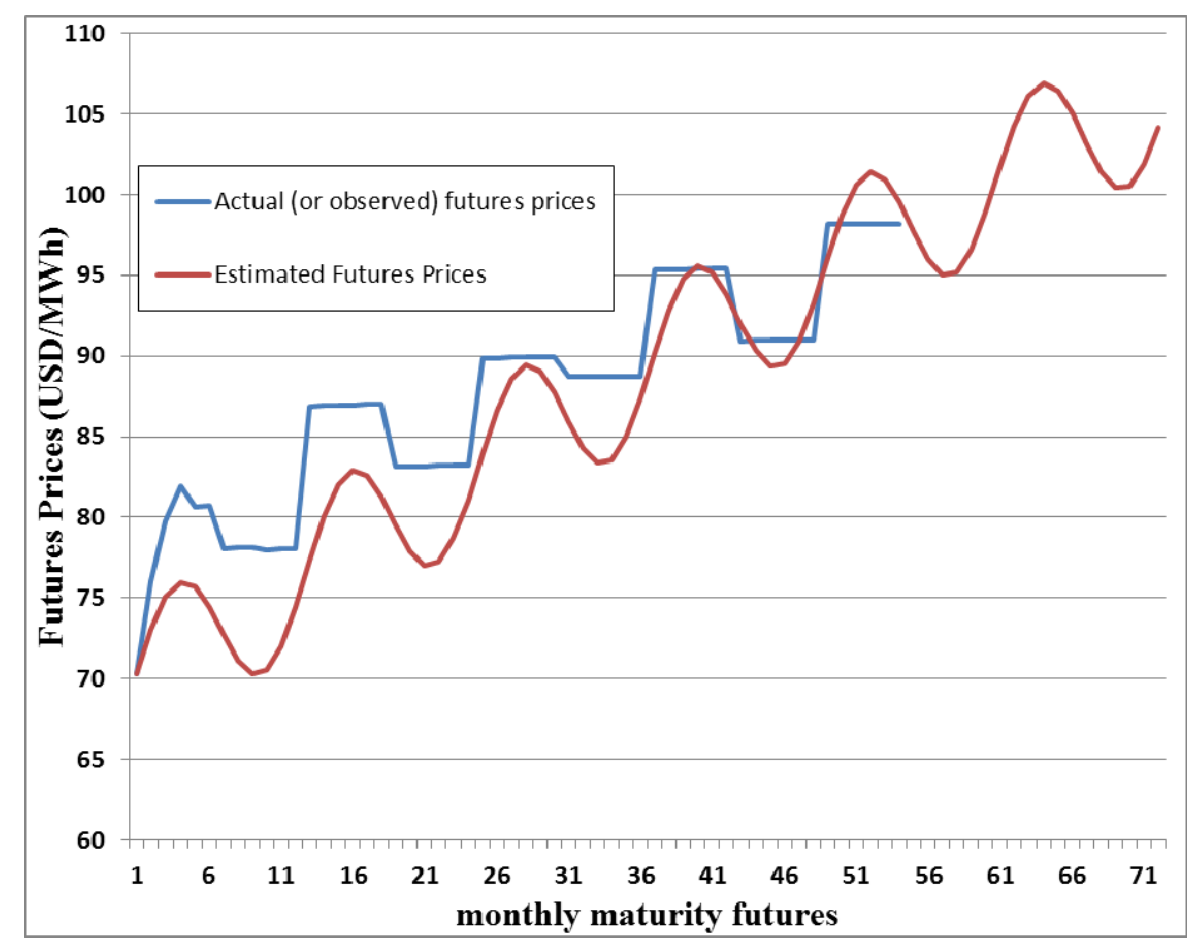

Figure 4: Observed and Estimated Base Electricity Futures quotes as of 08/31/2012 


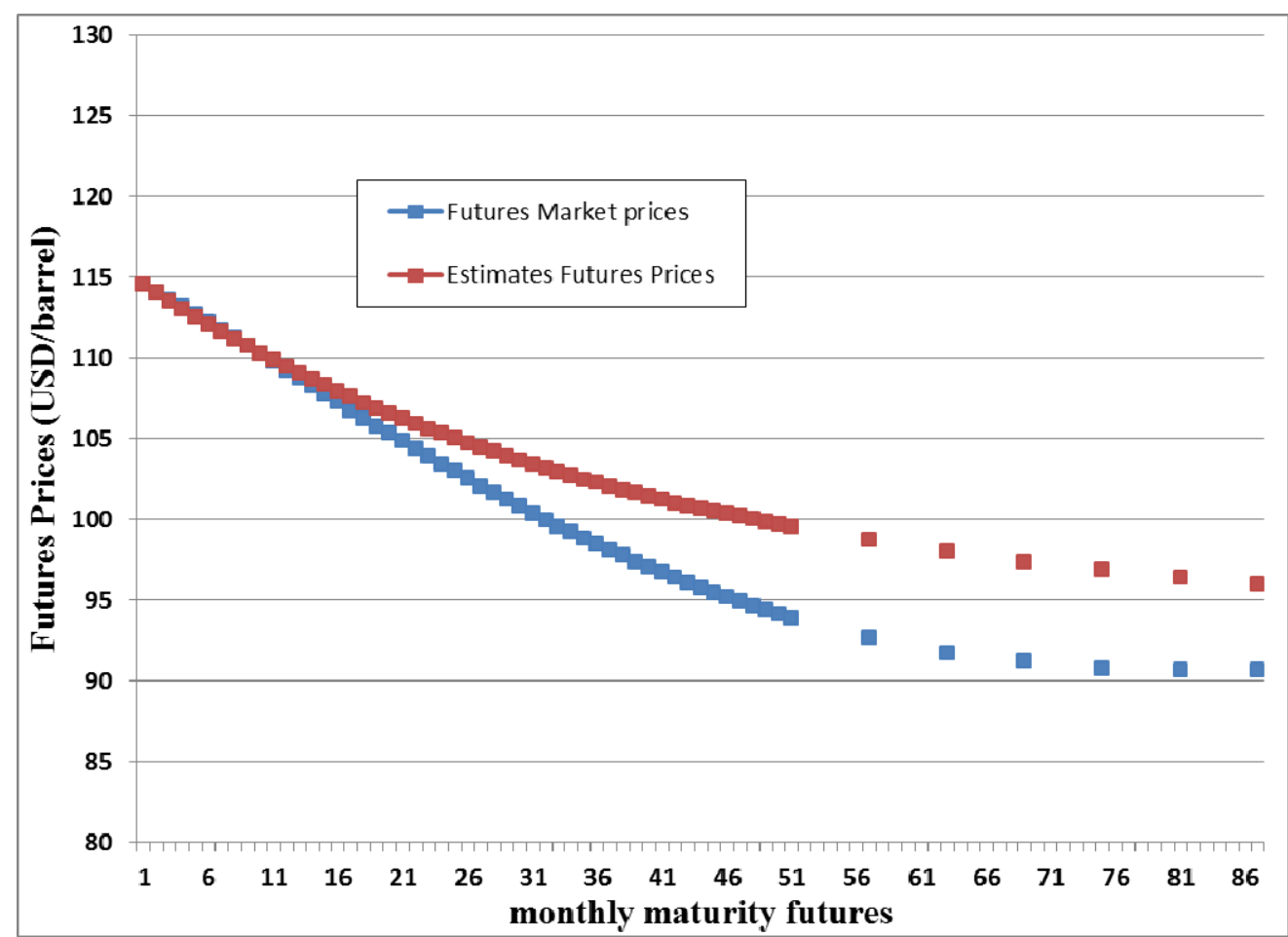

Figure 5: Observed and Estimated Oil Futures quotes as of 08/31/2012

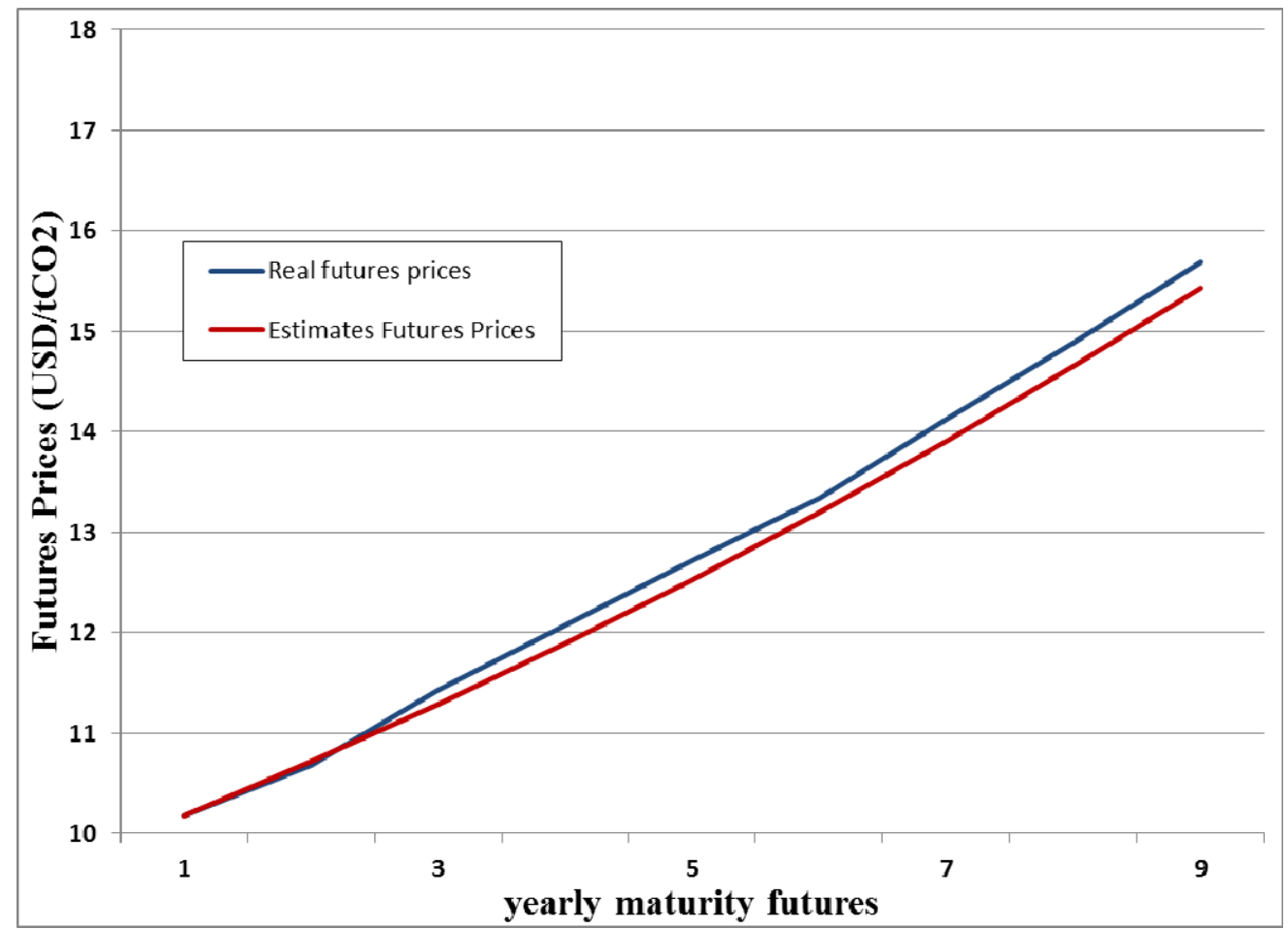

Figure 6: Actual and Estimated Carbon Futures quotes as of 08/31/2012 


\section{The Costs and Profits of Investment in CCS with EOR and DSF}

For the purpose of the analysis we define a baseline scenario with representative values based on the relevant literature. However, one should note that any project will have specific characteristics such as the distance between capture and storage or storage capacity available. Therefore, these would need to be accounted for changing the parameters accordingly.

It is also important to note that revenues and costs will take place in the following three stages: capture, transportation and storage. In addition and for illustrative purposes, it is assumed that the construction of the CCS unit will take 4 years since the investment decision is taken and before the plant is operational.

Finally, we are also assuming that once the investment project is approved (and implemented) the useful lifetime of the plant will be 20 years ${ }^{5}$. No additional decommissioning costs are considered for $\mathrm{CO}_{2}$-EOR projects as it is assumed that the decommissioning costs of the oil field will be incurred much later in time.

The costs and benefits per annum of an operational project are detailed below.

\subsection{Incremental coal-fired power plant cost with CCS}

In this section we compute the costs of a coal-fired power plant with CCS. In such a project, the existence of the CCS unit entails a loss of efficiency which translates in a lower electricity output for the same amount of fuel. This in turn means less revenue from electricity production. Logically, there is a shortfall in electricity production which will be covered by other electricity generating units that could be either renewables or gas-fired power plants. Table 6 shows the EIA estimates for cost and performance of coal-fired power plants. These are values are used in our work.

\begin{tabular}{|c|c|c|c|c|}
\hline Technology & $\begin{array}{c}\text { Overnight } \\
\text { Cost } \\
(2010 \$ / \mathrm{kW})\end{array}$ & $\begin{array}{c}\text { Variable } \\
\text { Operation \& } \\
\text { Maintenance } \\
\text { (O\&M) } \\
(2010 \\
\text { \$/MWh) }\end{array}$ & $\begin{array}{l}\text { Fixed } \\
\text { O\&M } \\
(2010 \\
\$ / \mathrm{kW})\end{array}$ & $\begin{array}{c}\text { Heat rate in } \\
2011 \\
\text { (Btu/KWh) }\end{array}$ \\
\hline Dual Unit Advanced PC & 2,844 & 4.25 & 29.67 & 8,800 \\
\hline $\begin{array}{l}\text { Dual Unit Advanced PC with } \\
\text { CCS }\end{array}$ & 4,579 & 9.05 & 63.21 & 12,000 \\
\hline
\end{tabular}

As it can be seen, CCS generates the following cost increases: 1,735 $\$ / \mathrm{kW}$ in Overnight cost, 4.80 $\$ / M W h$ in variable Operation and Maintenance (O\&M) costs and $33.54 \$ / \mathrm{kW}$ in Fixed O\&M cost.

\footnotetext{
${ }^{5}$ We additionally consider an alternative 40 year lifetime in the case of only DSF storage.
} 
Using the values in Table 6 the efficiency of the plant with and without CCS can be calculated. The results are shown in the Table 7.

\begin{tabular}{|l|c|c|c|}
\hline \multicolumn{1}{|c|}{ Table 7: Efficiency with and without CCS } \\
\hline \multicolumn{1}{|c|}{ Technology } & $\begin{array}{c}\text { Heat rate } \\
\text { in } 2011 \\
(\mathrm{Btu} / \mathrm{KWh})\end{array}$ & $\begin{array}{c}\text { Heat rate in } \\
2011 \\
(\mathrm{GJ} / \mathrm{MWh})\end{array}$ & Efficiency $^{6}$ \\
\hline Dual Unit Advanced PC & 8,800 & 9.284493 & 0.387743 \\
\hline $\begin{array}{l}\text { Dual Unit Advanced PC with } \\
\text { CCS }\end{array}$ & 12,000 & 12.66067 & 0.284345 \\
\hline
\end{tabular}

The use of CCS implies a efficiency loss of $10.34 \%$ (from $38.77 \%$ to $28.43 \%$ ) equivalent to $26.67 \%$ of the electricity that would generate without CCS.

If we now assume that $85 \%$ of emissions from a coal-fired power plant can be captured, the following calculations can be made:

Consider a plant with a capacity of $1000 \mathrm{MWe}$ which is working $80 \%$ of the time, i.e. 7,008 hours per year. Yearly production without CCS is thus $7,008,000 \mathrm{MWh}$. The numbers are shown in Table 8 below.

\begin{tabular}{|c|c|c|c|}
\hline Capacity installed without CCS (P1) & 1000 & MWe & \\
\hline Capacity factor & $80 \%$ & & \\
\hline Yearly operation & 7,008 & hours & \\
\hline Annual production & $7,008,000$ & MWh/year & \\
\hline Plant Efficiency without CCS (EF1) & $38.77 \%$ & & u \\
\hline HR & 8.3721 & GJ/MWh & $\stackrel{\bar{E}}{\epsilon}$ \\
\hline Fuel Energy needs & $65,065,726$ & GJ/year & $s$ \\
\hline Emission factor (100\% Efficiency) & 94.6 & $\mathrm{Kg} \mathrm{CO}_{2} / \mathrm{GJ}$ & \\
\hline $\mathrm{CO}_{2}$ Emissions & 0.878 & $\mathrm{tCO}_{2} / \mathrm{MWh}$ & \\
\hline Yearly emissions without CCS & $6,155,218$ & $\mathrm{tCO}_{2} /$ year & \\
\hline Capture Efficiency & $85 \%$ & & \\
\hline Annual capture with CCS & $5,231,935$ & $\mathrm{tCO}_{2} /$ year & U \\
\hline Annual emission with CCS & 923,283 & $\mathrm{tCO}_{2} /$ year & $\sum^{=}$ \\
\hline Plant Efficiency with CCS & $28.43 \%$ & & \\
\hline
\end{tabular}

\footnotetext{
${ }^{6}$ The efficiency is is equal to 3.6 divided by the Heat rate measured in GJ/MWh.
} 


\begin{tabular}{|l|rl|} 
Electricity consumed CCS & $1,868,800$ & $\mathrm{MWh} /$ year \\
Capacity installed with CCS (P2) & 733.33 & $\mathrm{MWe}$ \\
CSS Overnight Costs & 1,735 & $\$ / \mathrm{kW}$ \\
CSS Total Overnight Cost & $1,272.333$ & $\mathrm{M} \$$ \\
Variable O\&M cost & 4.80 & $\$ / \mathrm{MWh}$ \\
Total Variable O\&M Cost & 24.668 & $\mathrm{M} \$ /$ year \\
Fixed O\&M Cost & 33.54 & $\$ / \mathrm{kW}$ \\
Total Fixed O\&M Cost & 24.596 & $\mathrm{M} \$ /$ year \\
Total Fixed + Variable O\&M Cost & 49.264 & $\mathrm{M} \$ /$ year \\
\hline
\end{tabular}

Furthermore, with this information additional calculations can be made for the coal-fired power plant without CSS:

Fuel energy needs are: 7,008 $\times \mathrm{P} 1 \times \mathrm{HR}=65,065,726 \mathrm{GJ} / \mathrm{year}$.

Under these conditions the Coal Fired Power Plant without CCS will obtain a profit from selling the 7,008,000 MWh on the market.

If now consider that according to IPCC (2006) a plant burning bituminous coal has an emission factor of $94.6 \mathrm{~kg} \mathrm{CO} / \mathrm{GJ}$ under $100 \%$ efficiency conditions; we can calculate that

$3.6 * 94.6 / 1,000=0.34056 \mathrm{tCO}_{2} / \mathrm{MWh}$ under the $100 \%$ efficiency rate.

Therefore for $38.77 \%$ efficiency rate emission is $0.34056 / 0.3877=0.878 \mathrm{tCO}_{2} / \mathrm{MWh}^{7}$ The total emissions per year will thus be $6,155,218 \mathrm{tCO}_{2}$.

If we now consider that a CCS unit is installed, assuming that $85 \%$ of emissions are captured (IEA, 2008), then 5,231,935 $\mathrm{tCO}_{2}$ /year will stop from being emitted while the remaining 923,283 $\mathrm{tCO}_{2} /$ year will be emitted.

If 10.34 percentage points $(38.77 \% \rightarrow 28.43 \%)$ of efficiency is lost with CCS, it means that with the same input fuel less energy can be produced, i.e. 5,139,200 MWh/year. The total loss is thus $1,868,800 \mathrm{MWh} /$ year, accounting for $26.67 \%$ of total production. The installed capacity with CCS (P2 in Table 8) will be 733.33 MWe $(=5,139,200 / 7,008)$.

The Total variable O\&M cost is $24.668 \mathrm{M} \$$ year $(=5,139,200 \times 4.8 / 1,000,000)$ while the Total fixed O\&M cost is $24.596 \mathrm{M} \$$ year $(=733,333 \times 33.54 / 1,000)$.

From these calculations the following figures can be deduced:

a) $1,868,800 \mathrm{MWh}$ of electricity generation will be lost per year at a cost that can be expected to increase.

\footnotetext{
${ }^{7}$ According to IEA, 2008 for a coal-fuelled plant, emission are in the range of $743 \mathrm{~kg} / \mathrm{MWh}$ to $833 \mathrm{kd} / \mathrm{MWh}$. However, the IEA study assumes greater efficiency ( $44 \%$ for Pulverized Coal).
} 
b) 5,231,935 $\mathrm{tCO}_{2}$ /year will stop being emitted at a value that can also be expected to grow year by year. This could be considered as a benefit if $\mathrm{CO}_{2}$-EOR projects paired with DSF were eligible to take part in $\mathrm{CO}_{2}$ trading schemes. ${ }^{8}$

c) The cost of investing in CCS is $1,272.333 \mathrm{M \$}^{9}$ and the fixed and variable costs per annum amounts to $49.264 \mathrm{M} \$$.

\subsection{EOR Transportation cost}

This basic case described in this paper envisages the storage of $\mathrm{CO}_{2}$ in mature North Sea oil fields which are offshore storage. The storage in North America however is frequently onshore and thus the use of different estimates is recommended. In this case, we are also assuming a distance of approximately $400 \mathrm{~km}$ between the source of the $\mathrm{CO}_{2}$ and the oil field.

In this context, the pipeline investment cost is assumed to be $224.4758 \mathrm{M} \$$, with annual O\&M costs of $5.8364 \mathrm{M} \$ /$ year. $^{10}$ All these values are coherent with the existing literature.

Assuming that O\&M costs increases at the riskless interest rate, the total transportation cost at present value is $341.2032 \mathrm{M} \$$.

\subsection{EOR Storage Costs and Profits}

Finally we assume that a miscible ${ }^{11}$ project in the UK sector is going to be assessed, since, according to Tzimas et al (2005), most of the storage capacity in mature oilfields in the North Sea is located in the UK area. ${ }^{12}$

The $\mathrm{CO}_{2}$ needed varies with the field, but typical estimates range from $0.25-0.40 \mathrm{tCO}_{2}$ per barrel of oil produced (U.S. Carbon Sequestration Council, 2011). It is then assumed that with $\mathrm{CO}_{2}$-EOR further 3 barrels of oil can be extracted per tonne of $\mathrm{CO}_{2}$ injected while oil production is decreasing together with the need of $\mathrm{CO}_{2}$. The first year in which the oil is extracted, $\mathrm{I}_{0}=15.7 \mathrm{M}$ barrels can be obtained while and nothing will be obtained in the last year. The annual production is therefore:

$$
2 I_{0} e^{-v t}-I_{0}
$$

With $v=\ln (2) / 20$.

The total production in 20 year will be:

$$
I_{0}\left[\frac{2}{v}\left(1-e^{-20 v}\right)-20\right]=138.969 \mathrm{M}^{b^{2}} \text { arrels }^{13}
$$

and the $\mathrm{CO}_{2}$ injected wil be $46.323 \mathrm{M} \mathrm{tCO}_{2}$.

\footnotetext{
${ }^{8}$ It may also happen that only the part stored in DSF was eligible.

${ }^{9}$ This value of $1,272.333 \$ / \mathrm{kW}$ is within the range of IEA (2008) estimates, that is, from $600 \$ / \mathrm{kw}$ to 1,700 $\$ / \mathrm{kW}$.

${ }^{10}$ Based in Tzimas et al (2005) estimates for Piper oil field, converted to M\$, with the exchange rate of 1.2611 $\$ / €$, set by the ECB (European Central Bank) August 2012, where pipeline operation and maintenance costs were assessed as $2.6 \%$ of the capital cost.

${ }^{11}$ This refers to the fact that $\mathrm{CO}_{2}$ becomes miscible in crude oil once a certain basic pressure is exceeded that depends on the characteristics of the crude oil and the $\mathrm{CO}_{2}$ and on the reservoir conditions.

${ }^{12}$ Oil fields in the UK sector such as Forties, Claymore, N Cormorant, Ninian and Piper are miscible reservoirs. Statfjord (Norway/UK) is also miscible.

${ }^{13}$ This figure is very close from $139.7 \mathrm{M}$ barrels estimated b Tzimas el al (2005) for Piper oil field.
} 
For a $10.50 \$$ /barrel EOR operations cost (Gozalpour et al., 2005) the total EOR operation cost will be $1,459.175 \mathrm{M} \$$.

If retention efficiency is $60 \%$ as argued by Gozalpour et al., (2005), then $27.7956 \mathrm{M}$ tCO2 will be sequestered in the oil field.

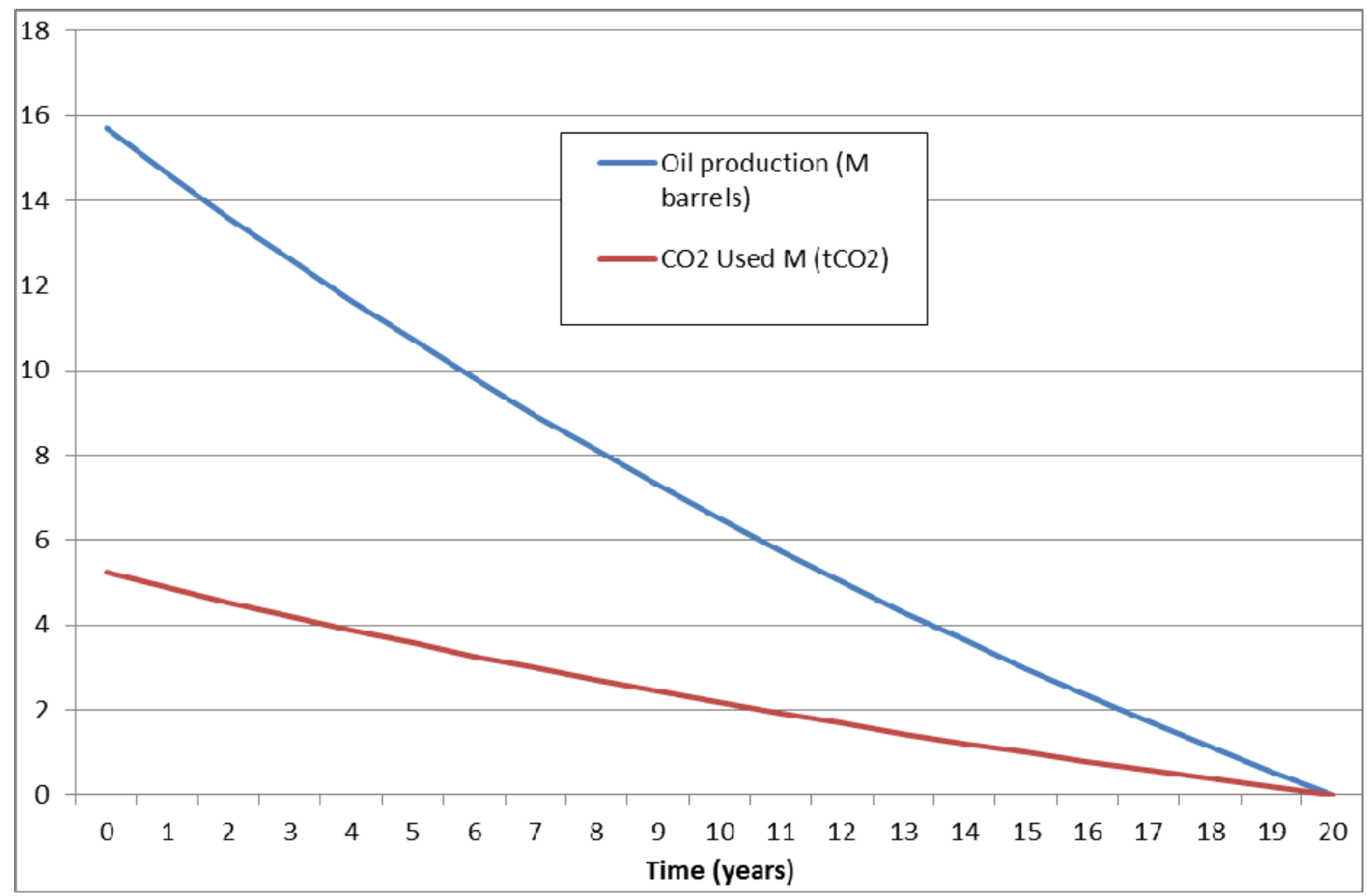

Figure 7: Actual oil production and $\mathrm{CO}_{2}$ used

\subsection{DSF Transportation and Storage Costs and Profits}

We have captured 104.6387 $\mathrm{M} \mathrm{tCO}_{2}$, of which $46.3230 \mathrm{M} \mathrm{tCO}_{2}$ are injected in the oil field (out of which only $27.7956 \mathrm{M} \mathrm{tCO} 2$ will be permanently stored). Therefore, $58.3157 \mathrm{M} \mathrm{tCO}_{2}$ will be injected in the DSF.

Using a transportation and storage cost de $3.075 \$ / \mathrm{tCO}_{2},{ }^{14}$ we have a total DSF transportation and storage cost of $179.321 \mathrm{M} \$$ for CO2-EOR paired with DSF. The profit will be the price of $83.295 \mathrm{M}$ $\mathrm{tCO}_{2}$ if the $\mathrm{CO}_{2}$ stored in the oil field was eligible to take part in $\mathrm{CO}_{2}$ trading schemes.

\subsection{Summary of Costs and Profits}

Table 9 displays a summary of profits and costs calculated before distinguishing between deterministic and stochastic. This example is estimated for 20 and 40 years of useful life for $\mathrm{CO}_{2}$ DSF.

\footnotetext{
${ }^{14}$ Mean of representative values used for Davidson et al. (2011) for large and small DSF.
} 


\begin{tabular}{|c|c|c|c|}
\hline & CO2-EOR + DSF (20 years) & $\mathrm{CO}_{2}$-DSF (20 years) & $\mathrm{CO}_{2}$-DSF (40 years) \\
\hline \multicolumn{4}{|l|}{ Stochastic Profits } \\
\hline Oil & 138.969 M barrels (20 years) & - & - \\
\hline $\mathrm{CO}_{2} \mathrm{EOR}$ & $27.7938 \mathrm{M} \mathrm{tCO}_{2}(20$ years $)$ & - & - \\
\hline $\mathrm{CO}_{2} \mathrm{DSF}$ & $58.3157 \mathrm{M} \mathrm{tCO}_{2}(20$ years $)$ & $5,231,935 \mathrm{tCO}_{2} /$ year & $5,231,935 \mathrm{tCO}_{2} /$ year \\
\hline \multicolumn{4}{|l|}{ Stochastic Costs } \\
\hline Electricity & $1,868,800 \mathrm{MWh} /$ year & $1,868,800 \mathrm{MWh} /$ year & $1,868,800 \mathrm{MWh} /$ year \\
\hline Determinist Costs & $4,237.312 \mathrm{M} \$$ & $2,579.377 \mathrm{M} \$$ & $2,901.141 \mathrm{M} \$$ \\
\hline CSS Capture Costs & $2,257.613 \mathrm{M} \$$ & $2,257.613 \mathrm{M} \$$ & $2,257.613 \mathrm{M} \mathrm{\$}$ \\
\hline EOR Transportation Costs & $341.203 \mathrm{M} \mathrm{\$}$ & - & - \\
\hline EOR Operation costs & $1,459.175 \mathrm{M} \$$ & - & - \\
\hline DSF Transportation \& Storage costs & $179.321 \mathrm{M} \mathrm{\$}$ & $321.764 \mathrm{M} \$$ & $643.528 \mathrm{M} \mathrm{\$}$ \\
\hline
\end{tabular}

\section{The Present Value of Investment in CCS with EOR and DSF}

\subsection{Valuation}

The first step is to calculate the value of an investment made at time $t$ when the initial conditions are $S_{t}^{E}-f_{E}(t)$ for the seasonally adjusted electricity price, $S_{t}^{O}$ for the oil price and $S_{t}^{A}$ for the carbon allowance prices. Under these conditions the present value is $V\left(S_{t}^{E}-f_{E}(t), S_{t}^{O}, S_{t}^{A}\right)$.

The value of such an investment will depend on the stochastic prices (Electricity, Oil and Carbon), the present value of deterministic investment and O\&M costs, the loss of efficiency of the coal-fired power plant and the quantity of oil obtained per tonne of $\mathrm{CO}_{2}$ injected. This is,

$$
V\left(S_{t}^{E}-f_{E}(t), S_{t}^{O}, S_{t}^{A}\right)=V_{A}+V_{O}-V_{E}-I \text {. }
$$

With a loss of $1,868,800 \mathrm{MWh} / \mathrm{year}$, assuming a lead time of $\tau_{1}=4$ years between the beginning of facilities construction and the end (EIA Annual Energy Outlook, 2012), we have: 


$$
\begin{gathered}
V_{E}=1,868,800 \times \int_{\tau_{1}}^{\tau_{2}} E\left(S_{t}^{E}-f_{E}(t)\right) e^{-r t} d t \\
=1,868,800 \times\left(\frac{\left(S_{0}^{i}-f_{i}(0)\right)-\frac{k_{S}^{i} S_{m}^{i}}{\lambda_{S}^{i}+k_{S}^{i}}}{\lambda_{S}^{i}+k_{S}^{i}+r}\left[e^{-\left(\lambda_{S}^{i}+k_{S}^{i}+r\right) \tau_{1}}-e^{-\left(\lambda_{S}^{i}+k_{S}^{i}+r\right) \tau_{2}}\right]+\frac{k_{S}^{i} S_{m}^{i}}{r\left(\lambda_{S}^{i}+k_{S}^{i}\right)}\left[e^{-r \tau_{1}}-e^{-r \tau_{2}}\right]\right)
\end{gathered}
$$

Otherwise, for oil profits:

$$
V_{O}=2 I_{0} e^{v \tau_{1}} \int_{\tau_{1}}^{\tau_{2}} E\left(S_{t}^{O}\right) e^{-(r+v) t}-I_{0} \int_{\tau_{1}}^{\tau_{2}} E\left(S_{t}^{O}\right) e^{-r t}
$$

For carbon sequestered in the oil field:

$$
V_{A 1}=\frac{2 \times 0.6}{3} \times I_{0} e^{v \tau_{1}} \int_{\tau_{1}}^{\tau_{2}} E\left(S_{t}^{A}\right) e^{-(r+v) t}-\frac{0.6}{3} I_{0} \int_{\tau_{1}}^{\tau_{2}} E\left(S_{t}^{A}\right) e^{-r t}
$$

The carbon injected in the DSF each year is:

$$
\frac{2}{3} I_{0}-\frac{2}{3} I_{0} e^{-v t}
$$

Therefore

$$
V_{A 2}=\frac{2}{3} \times I_{0} \int_{\tau_{1}}^{\tau_{2}} E\left(S_{t}^{A}\right) e^{-r t}-\frac{2}{3} I_{0} e^{\nu \tau_{1}} \int_{\tau_{1}}^{\tau_{2}} E\left(S_{t}^{A}\right) e^{-(r+v) t}
$$

The riskless interest rate is $1.49 \%$ and corresponds to the 10 years maturity UK debt (August 2012). ${ }^{15}$ If as we agreed, it takes 4 years to build the CCS unit $\left(\tau_{1}=4\right)$ since the investment decision is made (at $t=0$ ); henceforth it keeps working for 20 years (until $\tau_{2}=24$ ).

With these data we derive with the initial values of parameters for the Net Present Value (NPV) and other values that appear in Table 10.

\begin{tabular}{|lrl|}
\hline \multicolumn{2}{|l|}{ Table 10: Base Case Results CO2-EOR + CO2-DSF (20 years) } \\
\hline Net Present Value (NPV) & $+4,639.1$ & $\mathrm{M} \$$ \\
. Deterministic cost & $-4,237.3$ & $\mathrm{M} \$$ \\
. Electricity cost & $-4,091.8$ & $\mathrm{M} \$$ \\
. Oil profits & $+11,432.0$ & $\mathrm{M} \$$ \\
. Carbon profits EOR & +416.0 & $\mathrm{M} \$$ \\
\end{tabular}

${ }^{15}$ Source: European Central Bank. 


\begin{tabular}{|c|c|c|}
\hline . Carbon profits DSF & $+1,120.2$ & M \$ \\
\hline $\mathrm{NPV} / \mathrm{tCO}_{2}$ captured & 44.33 & $\$$ \\
\hline NPV/barrel & 33.38 & $\$$ \\
\hline
\end{tabular}

The figure of $+4,639.1 \mathrm{M} \$$ in Table 10 shows a positive return on investment in $\mathrm{CO}_{2}$-EOR with secondary DSF storage. These results are mainly due to the high prices of oil. It should be noted that the long-term equilibrium price (estimated from the futures market for oil) is $93.6795 \$ /$ barrel and that three barrels can be extracted per tonne of $\mathrm{CO}_{2}$.

Note that these results are markedly different from those of Tzimas et al. (2005) mainly for two reasons: (a) because the authors use two constant-price scenarios ( $\$ 25 /$ barrel and $\$ 35 /$ barrel) and (b) because they discount cash flows at a rate of $10 \%$, which means that they implicitly assume the same risk premium for all cash flows ' In our case, we use a spot and futures market valuation method for oil, carbon and electricity. With futures market prices being used, amounts are discounted at the riskless interest rate, as it is usually done when valuing derivatives, be they financial or commodities. ${ }^{16}$ The oil prices quoted in the futures markets and used in this paper (from 12/01/2009 to $08 / 31 / 2012$ ) are much higher than those used by Tzimas et al. (2005).

Moreover, our methodology considers the effect of uncertainty on investment. This uncertainty stems from volatility in the prices of oil, carbon and electricity, and is analysed in the following section.

Next the sensitivity of Net Present Value to different long-term equilibrium prices of oil on the futures market $\left(\frac{k_{S}^{O} S_{m}^{O}}{\lambda_{S}^{O}+k_{S}^{O}}\right)$ is analysed, to find the price at which the Net Present Value is zero. To that end we begin with the current price of oil ( $S_{0}^{O}=115.0470 \$ /$ barrel $)$ and maintain the estimated reversion speed $\left(\lambda_{S}^{O}+k_{S}^{O}=0.3054\right)$. The results are shown in Table 11 and Figure 8.

\begin{tabular}{|c|c|c|c|c|c|c|c|c|c|}
\hline Oil price ( $\$ /$ barrel) & 30 & 40 & 50 & 50.955 & 60 & 70 & 80 & 90 & 93.6795 \\
\hline NPV (M\$) & $-2,275$ & $-1,190$ & -104 & 0 & 982 & 2,068 & 3,154 & 4,240 & $4,639.1$ \\
\hline $\mathrm{NPV} / \mathrm{tCO}_{2}$ & -21.74 & -11.37 & -0.99 & 0 & 9.39 & 19.76 & 30.14 & 40.52 & 44.33 \\
\hline NPV/barrel & -16.37 & -8.56 & -0.75 & 0 & 7.07 & 14.88 & 22.69 & 30.51 & 33.38 \\
\hline
\end{tabular}

\footnotetext{
${ }^{16}$ Contract an operation in the futures market means a sure price for the purchase or sale of, e.g. a barrel of oil in the future, so it must be discounted at the risk-free interest rate. The exchange provides a mechanism that ensures that the contract will be honored.
} 


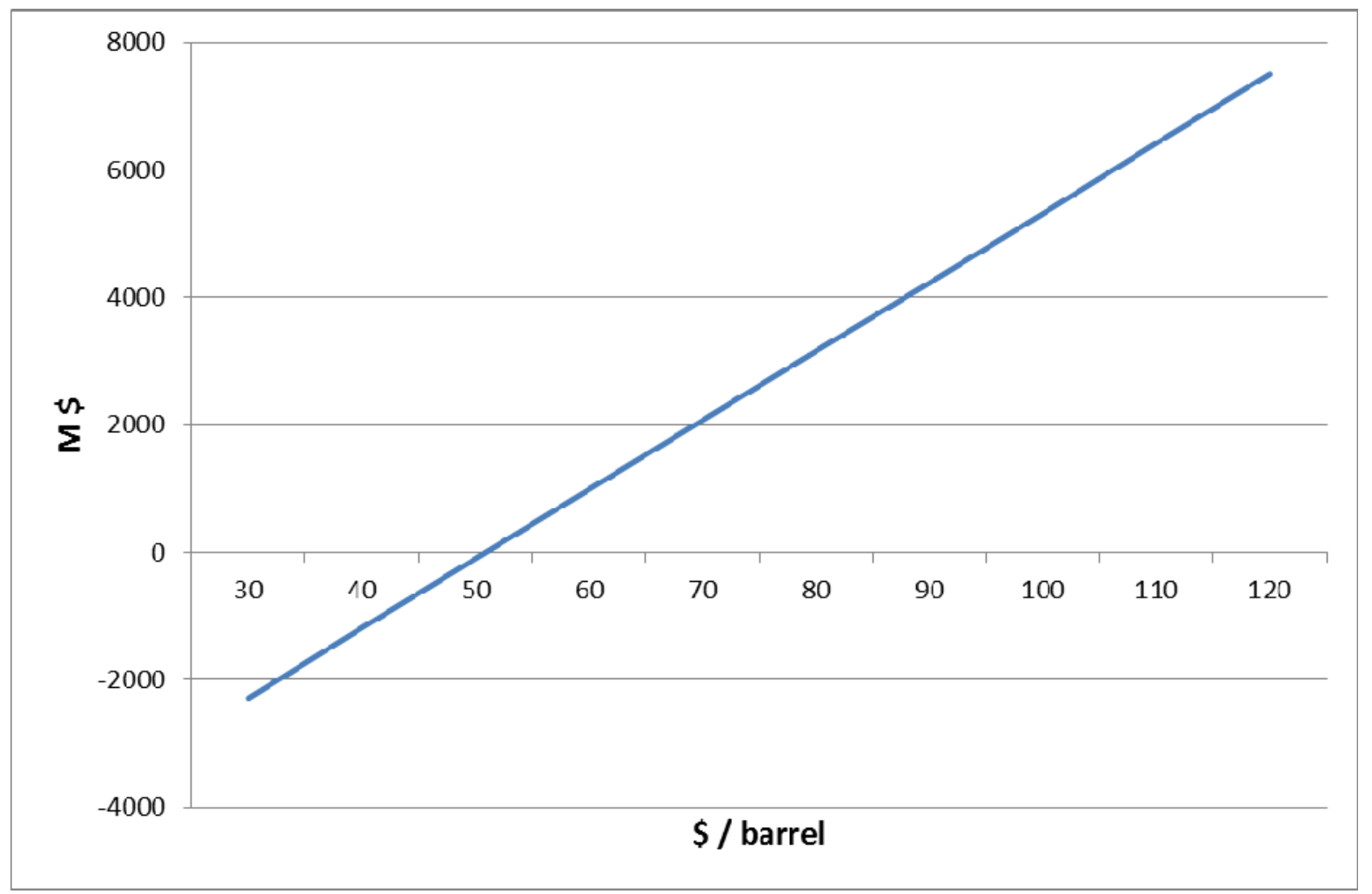

Figure 8: Net Present Value according to long-term equilibrium price on the futures market

For a price of $50.955 \$ /$ barrel our model gives NPV=0.

Let us also consider two special cases, the results for which are shown in Table 12:

A) When the $\mathrm{CO}_{2}$ permanently stored in the oil field is not eligible to take part in $\mathrm{CO}_{2}$ trading schemes. In that case it suffices to set $V_{A 1}=0$.

B) When there is no EOR, the total $\mathrm{CO}_{2}$ captured is injected in the DSF and it is eligible for $\mathrm{CO}_{2}$ trading schemes.

Table 12: Special cases

\begin{tabular}{|c|c|c|c|}
\hline & $\mathrm{No} \mathrm{CO}_{2}$-EOR trading & No EOR (20 years) & No EOR (40 years) \\
\cline { 2 - 4 } $\mathrm{NPV}(\mathrm{M} \$)$ & 4,223 & $-4,858$ & $-5,349$ \\
$\mathrm{NPV} / \mathrm{tCO}_{2}$ & 40.36 & - & - \\
$\mathrm{NPV} /$ barrel & 30.39 & - & - \\
\hline
\end{tabular}

For the no- $\mathrm{CO}_{2}$ EOR trading case, the NPV drops by $416 \mathrm{M} \$$, compared to the base case. In this case $\mathrm{NPV}=0$ when the long-term equilibrium price of oil is $54.79 \$ / \mathrm{barrel}$. An increase of $3.83 \$ / \mathrm{barrel}$ over the base case is needed to make the project profitable.

On the other hand, when $\mathrm{CO}_{2}$ is not used for EOR and is merely stored in DSF during 20 years the deterministic costs are 2,579 \$M (2,257.613 M \$ CSS Capture and 321.764 M \$ transportation and 
storage cost of $104.639 \mathrm{M} \mathrm{tCO}_{2}$ ) and the NPV is negative. The initial price of carbon $S_{0}^{A}$ would have to rise substantially for $\mathrm{CCS}$ to have at least $\mathrm{NPV}=0$. In this case $\mathrm{NPV}>0$ is obtained only for figures in excess of $37.02 \$ / \mathrm{tCO}_{2}$ (and subsequently increase with a drift of 5.208\%).

At the actual carbon price, in the No EOR case with storage during 40 years, the NPV is mostly negative. That is, a higher carbon price would be needed to make the investment profitable.

Sensitivity to changes in the deterministic costs of investment in CCS, transportation, storage and EOR operation can be analysed. The results are shown in Table 13.

Table 13: Sensitivity to changes in deterministic costs (NPV=0)

\begin{tabular}{|c|ccc|c|}
\hline \multirow{2}{*}{$\begin{array}{c}\text { Deterministic } \\
\text { Cost }\end{array}$} & \multicolumn{3}{|c|}{ Long Term Oil Price } & \multirow{2}{*}{$\mathrm{CO}_{2}$ Price } \\
\cline { 2 - 3 } & Base Case & No CO2 EOR trading & No CO2 trading & No EOR \\
\hline 0 & 50.95 & 54.79 & 65.10 & 37.02 \\
$+1000 \mathrm{M} \$$ & 60.16 & 64.00 & 74.31 & 42.57 \\
$+2000 \mathrm{M} \$$ & 69.37 & 73.21 & 83.52 & 48.12 \\
\hline
\end{tabular}

Without the option to wait, storing during 20 years, and without EOR, when there is a cost increase of $1 \mathrm{M} \$$, the initial carbon price should rise to $42.57 \$ / \mathrm{tCO}_{2}$ and subsequently increase with a drift of $5.208 \%$. With lower growth, the break-even price must be greater: for a increase of $1 \mathrm{M} \$$ and growth of $2.5 \%$ it is $63.54 \$ / \mathrm{tCO}_{2}$, and with the same increase and zero growth $89.99 \$ / \mathrm{tCO}_{2}$. With longer time (40 years) storage in the DSF the initial carbon price of $19.63 \$ / \mathrm{tCO}_{2}$ can be lower, equivalent to a constant carbon price of $73.91 \$ / \mathrm{tCO}_{2}$. Therefore, it can be argued that the expected growth of carbon price and the investment useful life play an important role in the investment decision without uncertainty.

\section{The Option Value of Investment in CCS with EOR}

This section considers the valuation of investment when the decision whether to invest or not can be made at any time during a given horizon. Taking into account that the oil fields in the UK region of the North Sea are close to maturity there is a real possibility of $\mathrm{CO}_{2}$-EOR paired with $\mathrm{CO}_{2}$-EOR type of investment. However, if the current infrastructures were dismantled this investment option would lose much of its value.

We thus assume that there is an option to decide whether to make an investment of this type over the next ten years, and that it can be exercised at any time. Technically, this would be an American type ${ }^{17}$ option with three sources of risk, corresponding to the prices of oil, carbon and electricity. ${ }^{18}$

To develop the investment lattice, the time $T=10$ years in which the investment is available is divided into $n$ steps each of size $\Delta t=T / n$. In our case we take $\mathrm{n}=60$, i.e. 6 steps per year.

\footnotetext{
${ }^{17}$ This refers to the possibility to exercise it at any time within the 10 years period.

${ }^{18}$ We use an option valuation lattice similar to the one used by Abadie et al. (2011).
} 
Starting from initial values $V\left(S_{0}^{E}-f_{E}(0), S_{0}^{O}, S_{0}^{A}\right)$ after the first step we can compute the values $V\left(\left(S_{0}^{E}-f_{E}(0)\right) e^{\sigma_{E} \sqrt{\Delta t}}, S_{0}^{O} e^{\sigma_{O} \sqrt{\Delta t}}, S_{0}^{A} e^{\sigma_{A} \sqrt{\Delta t}}\right)$ when the three prices rise with probability $p_{\text {uuu }}^{*}$.

Similarly we derive the remaining nodes that arise in the first step, for example, $V\left(\left(S_{0}^{E}-f_{E}(0)\right) e^{-\sigma_{E} \sqrt{\Delta t}}, S_{0}^{O} e^{-\sigma_{O} \sqrt{\Delta t}}, S_{0}^{A} e^{-\sigma_{A} \sqrt{\Delta t}}\right)$ when the three prices fall with probability $p_{d d d}^{*}$. After the first step the initial value $S_{0}^{E}-f_{E}(0)$ moves to one of two possible values: $\left(S_{0}^{E}-f_{E}(0)\right) u_{E}$ or $\left(S_{0}^{E}-f_{E}(0)\right) d_{E}$, where $u_{E}=e^{\sigma_{E} \sqrt{\Delta t}}$ and $d_{E}=\frac{1}{u_{E}}=e^{-\sigma_{E} \sqrt{\Delta t}}$.

After $i$ steps, with $j_{E}, j_{O}$ and $j_{A}$ upward moves, a value of $V\left(\left(S_{0}^{E}-f_{E}(0)\right) e^{\sigma_{E} \sqrt{\Delta t}\left(2 j_{E}-i\right)}\right.$, $\left.S_{0}^{O} e^{\sigma_{L} \sqrt{\Delta t}(2 j} O^{-i)}, S_{0}^{A} e^{\sigma_{E} \sqrt{\Delta t}\left(2 j_{A}-i\right)}\right)$ will be reached. It can be shown that the tree branches recombine; thus, the same value results from a rise followed by a drop as from the other way round.

At the final time $T$ the possible combinations of values can be represented by means of a cube. At the earlier time $T-\Delta t$ another smaller cube describes the set of feasible values. There will be some probabilities of moving from each node to eight possible states of the cube at time $T$.

At time $T$ the option value is the maximum of investing (thus obtaining an NPV) or zero.

$$
W_{T}=\max \left(V\left(S_{T}^{E}-f_{E}(T), S_{T}^{O}, S_{T}^{A}\right), 0\right),
$$

In a lattice with $n$ steps at the final time there will be $(n+1)^{3}$ nodes, and in the time just before $n^{3}$ nodes.

At earlier times, i.e. for $t<T$ the value at each node in the lattice is:

$$
\begin{gathered}
W_{t}=\max \left(V\left(S_{t}^{E}-f_{E}(t), S_{t}^{O}, S_{t}^{A}\right), e^{-r \Delta t}\left(p_{u u u}^{*} W^{+++}+p_{u u d}^{*} W^{++-}\right.\right. \\
\left.+p_{u d u}^{*} W^{+-+}+p_{u d d}^{*} W^{+--}+p_{d u u}^{*} W^{-++}+p_{d u d}^{*} W^{-+-}+p_{d d u}^{*} W^{--+}+p_{d d d}^{*} W^{---}\right)
\end{gathered}
$$

The Net Present Value (NPV) is computed each time and is compared with the second term, namely the value of delaying the investment. The higher of them is finally chosen. $W^{+++}$denotes the value reached when moving from the current node to another where the three variables have moved upward. The latter value has been already derived since the lattice is solved backwards.

Note that the value of the investment in $t<T$ is computed for oil between $t+4$ and $t+24$, i.e. starting four years after the investment decision is made and running until the end of the useful life of the CCS unit. Therefore, $\tau_{1}=t+4$ and $\tau_{2}=t+24$. Similarly for carbon and electricity $\tau_{1}=t+4$ and $\tau_{2}=t+24$.

Proceeding backwards through the lattice we get an amount which shows the value of the option to invest, which cannot be negative. ${ }^{19}$

\footnotetext{
${ }^{19}$ As the 3D binomial tree needs a lot of computing capacity it might be necessary to keep only the two cubes in which the calculations are being made (those of times $t$ and $t+\Delta t$ ) and re-use the free space for later computations.
} 
By changing the long-term oil price value $\frac{k_{S}^{O} S_{m}^{O}}{k_{S}^{O}+\lambda_{S}^{O}}$ different values can be derived for $V\left(S_{t}^{E}-f_{E}(t), S_{t}^{O}, S_{t}^{A}\right)$. Those combinations for which the NPV is just higher than the value of postponing the decisions provide the trigger prices for investment initially to be optimal.

The results of the option valuation appear in Table 14. Now the trigger price for an optimum investment is $89.29 \$ /$ barrel, somewhat higher than the $50.955 \$ /$ barrel in the base case. The results show a significant influence of the impact of the carbon price growth rate, significantly higher than the risk-free interest rate, which leads to the need for higher oil prices to make the investment in time $\mathrm{t}=0$, when there is the possibility to postpone the investment. In the case $k_{S}^{A}+\lambda_{S}^{A}=0$ the trigger price will be 62.38 \$/barrel.

\begin{tabular}{|c|c|c|c|c|c|c|c|c|}
\hline \multicolumn{9}{|c|}{ Table 14: Option Value } \\
\hline Oil price (\$/barrel) & 30 & 40 & 50 & 50.955 & 60 & 70 & 80 & 89.29 \\
\hline NPV (M\$) & $-2,275$ & $-1,190$ & -104 & 0 & 982 & 2,068 & 3,154 & 4,163 \\
\hline Continuation Value & 724 & 846 & 1,017 & 1,038 & 1,319 & 2,099 & 3,157 & 4,163 \\
\hline Option Value & 724 & 846 & 1,017 & 1,038 & 1,319 & 2,099 & 3,157 & 4,163 \\
\hline
\end{tabular}

We have argued that if the decision to invest is not taken in the following years the costs may significantly increase because the infrastructures could be dismantled. If we now assume a cost increase of 1,000 million if the investment is delayed beyond the initial moment $\mathrm{t}=0$, we obtain a new trigger price of $60.86 \$ /$ barrel. In this last case the value is next of the NPV because there are few incentives to delay the investment.

Table 15 shows the trigger price sensitivity to changes in CCS costs, in two cases: when $k_{S}^{A}+\lambda_{S}^{A}=0$ and when the project is excluded from participating in the $\mathrm{CO} 2$ market.

\section{Table 15: Trigger price sensitivity to changes in deterministic costs under uncertainty}

\begin{tabular}{|c|cc|}
\hline $\begin{array}{c}\Delta \text { Deterministic } \\
\text { Cost }\end{array}$ & \multicolumn{2}{|c|}{ Long Term Oil Price } \\
\cline { 2 - 3 }$(\mathrm{M} \$)$ & Base Case with & No CO2 EOR trading \\
\hline 0 & $k_{S}^{A}+\lambda_{S}^{A}=0$ & \\
\hline $1000 \mathrm{M} \$$ & 62.38 & 67.14 \\
& 72.17 & 79.82 \\
\hline
\end{tabular}

Finally for the case of non-EOR the analysis is: When carbon is merely stored in DSF and oil is not extracted, the trigger price depends on its volatility and its growth rate. For zero growth $\left(k_{A}+\lambda_{A}=0\right)$, the results shown in Table 16 are obtained: 


\begin{tabular}{|c|c|c|c|}
\hline \multicolumn{4}{|c|}{ Table 16: Sensitivity of Carbon Trigger Price without EOR $\left(\$ / \mathrm{tCO}_{2}\right)$} \\
\hline \multicolumn{4}{|c|}{ Volatility $\sigma_{A}$} \\
\hline 0.05 & 0.10 & 0.20 & 0.30 \\
\hline 85.34 & 96.16 & 136.95 & 203.40 \\
\hline
\end{tabular}

Now there is uncertainty and also the possibility of investing within a time interval and not only in the outset.

It should be kept in mind that if the expected rise in the price of carbon in risk-neutral world is greater than the riskless interest rate, the rational decision will be to postpone the investment. What is the size of the subsidy provided only at the outset that would offset this effect?

If the subsidy is only available at the initial moment then the value of waiting is the same as in the previous cases. The minimum subsidy to invest in the initial moment will be exactly the difference between the continuation value and the net present value in that moment, namely:

$$
\text { Subsidy }=\max (\text { Wait }-N P V, 0) \text {. }
$$

The results in terms of volatility, the initial carbon price and its rate of growth in the futures market, are detailed in the Table 17. This table provides a numerical evaluation of the following conclusions:

a) When the carbon price increases, the NPV also increases, but so does the waiting value.

b) When the growth rate of carbon price in the futures market $\left(\alpha_{A}-\lambda_{A}\right)$ is greater than $r$, then the value of waiting grows significantly and discourages the immediate investment. The opposite occurs when $\left(\alpha_{A}-\lambda_{A}\right)<r$.

c) The NPV is favoured by a high value of $\left(\alpha_{A}-\lambda_{A}\right)$, but the effect is not strong enough to offset for the negative effect produced by increased wait value.

d) Lower volatility has a very significant effect, reducing the continuation value and thus encouraging investment earlier.

e) The more favourable combinations for investing immediately with low volatility, high initial carbon price and low expected growths with $\left(\alpha_{A}-\lambda_{A}\right)<r$.

\begin{tabular}{|c|c|c|c|c|c|c|}
\hline \multicolumn{7}{|c|}{ Table 17: Subsidy (M\$) without EOR } \\
\hline \multirow{2}{*}{$S_{0}^{A}$} & \multirow{2}{*}{$\alpha_{A}-\lambda_{A}$} & \multirow{2}{*}{ NPV } & \multicolumn{2}{|c|}{$\sigma_{A}=0.4535$} & \multicolumn{2}{c|}{$\sigma_{A}=0.30$} \\
\cline { 4 - 7 } & & & Wait & Subsidy & Wait & Subsidy \\
\hline 40 & 0.00 & $-3,261$ & 981 & 4,242 & 409 & 3,671 \\
50 & 0.00 & $-2,409$ & 1,435 & 3,844 & 711 & 3,119 \\
60 & 0.00 & $-1,556$ & 1,931 & 3,487 & 1,083 & 2,639 \\
70 & 0.00 & -704 & 2,470 & 3,173 & 1,517 & 2,221
\end{tabular}




\begin{tabular}{|c|c|c|c|c|c|c|}
\hline 80 & 0.00 & 149 & 3,034 & 2,885 & 2,004 & 1,855 \\
\hline 40 & 0.01 & $-2,762$ & 1,418 & 4,180 & 708 & 3,470 \\
\hline 50 & 0.01 & $-1,784$ & 2,027 & 3,811 & 1,171 & 2,955 \\
\hline 60 & 0.01 & -807 & 2,691 & 3,498 & 1,717 & 2,524 \\
\hline 70 & 0.01 & 171 & 3,389 & 3,218 & 2,329 & 2,159 \\
\hline 80 & 0.01 & 1,148 & 4,122 & 2,974 & 3,000 & 1,852 \\
\hline 40 & 0.05208 & 536 & 6,542 & 6,006 & 5,330 & 4,794 \\
\hline 50 & 0.05208 & 2,338 & 8,821 & 6,483 & 7,595 & 5,257 \\
\hline 60 & 0.05208 & 4,140 & 11,163 & 7,023 & 9,968 & 5,829 \\
\hline 70 & 0.05208 & 5,942 & 13,566 & 7,625 & 12,413 & 6,472 \\
\hline 80 & 0.05208 & 7,743 & 15,995 & 8,252 & 14,900 & 7,157 \\
\hline \multirow{2}{*}{$S_{0}^{A}$} & \multirow{2}{*}{$\alpha_{A}-\lambda_{A}$} & \multirow[t]{2}{*}{ NPV } & \multicolumn{2}{|c|}{$\sigma_{A}=0.20$} & \multicolumn{2}{|c|}{$\sigma_{A}=0.10$} \\
\hline & & & Wait & Subsidy & Wait & Subsidy \\
\hline 40 & 0.00 & $-3,261$ & 114 & 3,375 & 2 & 3,263 \\
\hline 50 & 0.00 & $-2,409$ & 275 & 2,684 & 17 & 2,426 \\
\hline 60 & 0.00 & $-1,556$ & 524 & 2,080 & 82 & 1,639 \\
\hline 70 & 0.00 & -704 & 861 & 1,564 & 251 & 955 \\
\hline 80 & 0.00 & 149 & 1,281 & 1,132 & 574 & 425 \\
\hline 40 & 0.01 & $-2,762$ & 277 & 3,038 & 18 & 2,779 \\
\hline 50 & 0.01 & $-1,784$ & 593 & 2,377 & 112 & 1,897 \\
\hline 60 & 0.01 & -807 & 1,032 & 1,839 & 367 & 1,174 \\
\hline 70 & 0.01 & 171 & 1,577 & 1,407 & 822 & 652 \\
\hline 80 & 0.01 & 1,148 & 2,211 & 1,063 & 1,463 & 315 \\
\hline 40 & 0.05208 & 536 & 4,557 & 4,021 & 4,030 & 3,494 \\
\hline 50 & 0.05208 & 2,338 & 6,911 & 4,573 & 6,593 & 4,255 \\
\hline 60 & 0.05208 & 4,140 & 9,386 & 5,247 & 9,193 & 5,054 \\
\hline 70 & 0.05208 & 5,942 & 11,922 & 5,981 & 11,800 & 5,859 \\
\hline 80 & 0.05208 & 7,743 & 14,491 & 6,748 & 14,407 & 6,664 \\
\hline
\end{tabular}

\section{Conclusions}

CCS is part of the technological options that should be carefully addressed in the near future to help in the transition towards a low carbon energy system. The possibility to combine the CCS with EOR in an operating coal-fired plant is one of the potential projects that are been analysed in Europe. The use of $\mathrm{CO}_{2}$ for EOR paired with storage in DSF could effectively help to support CCS demonstration projects, reduce costs and thus guarantee the future economic viability of power plants incorporating both EOR and CCS technologies.

In this paper we have analysed how the three main sources of uncertainty might affect investment decision for such a project. These uncertainties are the price of electricity, the price of oil and the 
price of carbon allowances. We have also considered the possibility to only opt for storage $\mathrm{CO} 2$ in Deep Saline Formations (DSF).

By developing a stochastic model calibrated with UK data we have shown that these investments CCS with EOR face a cost increase in operation and maintenance and efficiency loss and therefore are not highly profitable at current oil prices for investment in the North Sea. Only investments with EOR and secondary DSF storage can be profitable (NPV $>0$ ) with a high long term equilibrium price for oil higher than $50.95 \$ /$ barrel. This price will be $60.16 \$$ if costs grow by 1 billion $\$$. These results differ from Tzimas et al (2005) which uses constant price scenarios for oil. We have improved the analysis by using futures market quotations on the one hand and by introducing the effect of uncertainty on the other one. When the investment decision can be made at any time, i.e. there exist an option value, then the trigger value for optimal investment is significantly higher, $89.29 \$ /$ barrel. This number is very close to the long-term futures price of $93.68 \$ /$ barrel. Therefore, any increase in costs that would raise this trigger price could cause a delay in the investments.

If the investment decision is not made in the following years the infrastructure could be dismantled and thus the cost could significantly increase, in this case the trigger price drops significantly.

Two special cases are also considered: when $\mathrm{CO} 2$ is permanently stored in the oilfields together with a DSF and when no EOR exists and all CO2 is injected in DSF.

Lohwasser and Madlener (2012) highlight the importance of investment cost for the deployment of CCS in Europe. With this in mind, we have also analysed in this paper the existence of a wide range of investment costs in CCS through a sensitivity analysis.

The paper shows that actual carbon prices and their trend and volatility do not significantly contribute to generate major incentives for such technologies $\left(\mathrm{CO}_{2}\right.$-DSF). With current carbon prices the investment in CCS without EOR in the North Sea can be highly unprofitable. We need an initial carbon price of at least $19.63 \$ / \mathrm{tCO}_{2}$ and growing by $5.208 \%$ annually to obtain NPV=0. This is equivalent to a constant carbon price of $73.91 \$ / \mathrm{tCO}_{2}$.

As the expected increase in the price of carbon in risk neutral world is greater that the riskless interest rate, a rational decision would be to postpone investment decision without EOR. Therefore, significantly higher prices for oil would be necessary to decide on making the investment under these conditions. This opens the door for considering the possibility to design effective subsidy schemes that support early investment decision. These subsidies should, at least, equate the value of postponing the investment decision with the net present value of the investment, but the subsidies are very high run into billions of dollars.

This methodology is indicative of the type of analysis needed to understand what drives investment decision in CCS and can be easily adapted for other projects such as EGR or other industrial plants that use CCS.

Acknowledgements: Luis M. Abadie and Ibon Galarraga are grateful for financial support received from Fundación Repsol under the Low Carbon Programme (www.lowcarbonprogramme.org). The authors also thank the Research Council of Norway for partial support under the project "Strategic Challenges in International Climate and Energy Policy (CICEP)" (http://www.cicep.uio.no/english/).

Luis M. Abadie also gratefully acknowledges the support of the Spanish Ministry of Science and Innovation through the research project ECO2011-25064. 


\section{References}

Abadie, L.M. and Chamorro, J.M. 2008. European CO2 prices and carbon capture investments. Energy Economics. 30. 2992-3015.

Abadie, L.M., Chamorro, J.M. and González-Eguino, M. 2011. Optimal abandonment of EU coalfired stations. The Energy Journal. 32. 175-207.

Azar, C., Lindgren, K., Larson, E. and Möllersten, K. 2006. Carbon capture and storage from fossil fuels and biomass - costs and potential role in stabilizing the atmosphere. Climatic Change. 74 , 47-79.

Davidson, C.L., Dahowski, R.T. and Dooley, J.J. 2011. A quantitative comparison of the cost of employing EOR-coupled CCS supplemented with secondary DSF storage for two large $\mathrm{CO}_{2}$ point sources. Energy Procedia. 4, 2361-2368.

DECC. 2012. CCS Roadmap - Supporting Deployment of Carbon Capture and Storage in the UK, London.

de Coninck, H., Flach, T., Curnow, P., Richardson, P., Anderson, J., Shackley, S., Sigurthorssonb, G. and Reinerf, D. 2009. The acceptability of $\mathrm{CO}_{2}$ capture and storage (CCS) in Europe: An assessment of the key determining factors. Part 1. Scientific, technical and economic dimensions. International Journal of Greenhouse Gas Control. 3, 333-343.

EIA. 2010. Update Estimates of Power Plant Capital and Operating Costs.

http://www.eia.gov/oiaf/beck_plantcosts/pdf/updatedplantcosts.pdf

EIA. 2012. Annual Energy Outlook 2012.

Global Status of Large-Scale Integrated CCS Projects: June 2012 Update. Global CSS Institute, Canberra. http://www.globalccsinstitute.com/publications/global-status-ccs-update-june-2012

Gozalpour, F., Ren, S.R., and Tohidi, B. 2005. $\mathrm{CO}_{2}$ EOR and storage in oil reservoirs. Oil and Gas Science and Technology. 60, 537-546.

Haszeldine, R.S. 2009. Carbon capture and storage: How green can black be?. Science. 325, 16471652.

Höller, S. and Viebahn, P. 2011. Assessment of CO2 storage capacity in geological formations of Germany and Northern Europe. Energy Procedia. 4, 4897-4904.

IEA. 2007. World Energy Outlook 2007. OECD/IEA.

IEA. 2008. $\mathrm{Co}_{2}$ Capture and Storage: A Key Carbon Abatement Option.

IEA. 2011. World Energy Outlook 2011. OECD/IEA, Paris.

Intergovernmental Panel on Climate Change (IPCC). 2005. Special Report on Carbon Dioxide Capture and Storage. Cambridge University Press, Cambridge, U.K. and New York, U.S.A.

IPCC. 2006. Guidelines for National Greenhouse Gas Inventories.

Johnsson F., Reiner, D., Itaoka, K. and Herzog, H. 2010. Stakeholder attitudes on Carbon Capture and Storage-An international comparison. International Journal of Greenhouse Gas Control. 4, 410418. 
Lohwasser, R. and Madlener, R. 2012. Economics of CCS for coal plants: Impact of investment cost and efficiency on market diffusion in Europe. Energy Economics. 34, 850-863.

Luderer, G., Bosetti, V., Jakob, M., Leimbach, M., Steckel, J.C., Waisman, H. and Edenhofer, O. 2012. The economics of decarbonizing the energy system - results and insights from the RECIPE model intercomparison. Climatic Change. 114, 9-37.

NMyhrvold, N.P., Caldeira,K. 2012. Greenhouse gases, climate change and the transition from coal to low-carbon electricity. Environmental Research Letters. 7.

Middleton,R. S., Kuby, M. J., Wei, R., Keating, G. N. and Pawar, R. J. 2012. A dynamic model for optimally phasing in $\mathrm{CO} 2$ capture and storage infrastructure. Environmental Modelling and Software. Volume 37, November, pages 193-205.

Shackley, S., Waterman, H., Godfroij, P., Reiner, D., Anderson, J., Draxlbauer, K., de Conick, H., Groenenberg, H., Flach, T. and Sigurthorsson, G. 2007. Stakeholder Perceptions of CO2 Capture and Storage in Europe: Results from the EU-funded ACCSEPT Survey; Deliverable D3.1 from ACCSEPT - Main Report.

Shackley, S., Reiner, D., Upham, P., de Coninck, H., Sigurthorsson, G. and Anderson, J. 2009. The acceptability of $\mathrm{CO} 2$ capture and storage (CCS) in Europe: An assessment of the key determining factors - Part 2. The social acceptability of CCS and the wider impacts and repercussions of its implementation. International Journal of Greenhouse Gas Control. 3, 344-356.

Szulczewski, M.L., MacMinn, C.W., Herzog, H.J. and Juanes, R. 2012. Lifetime of carbon capture and storage as a climate-change mitigation technology. Proceedings of the National Academy of Sciences of the United States of America (PNAS). 109, 5185-5189.

Tzimas, E., Georgakaki, A., Cortes, G. and Peteves, S.D., .2005. Enhanced Oil Recovery using Carbon Dioxide in the European Energy System. Report EUR 21895 EN. http://science.uwaterloo.ca/ mauriced/earth691duss/CO2_General\%20CO2\%20Sequestration\%20materilas/CO2_EOR_Misciblein\%20Europe21 895EN.pdf

U.S. Carbon Secuestration Council. 2011. Enhanced Oil Recovery \& CCS.

http://www.uscsc.org/Files/Admin/Educational_Papers/Enhanced\%20Oil\%20Recovery $\% 20$ and $\% 20 \mathrm{C}$ CS-Jan\%202011.pdf

van den Broek, M., Brederode, E., Ramírez, A., Kramers, L., van der Kuip, M., Wildenborg, T., Turkenburg, W. and Faaij, A. 2010. Designing a cost-effective CO2 storage infrastructure using a GIS based linear optimization energy model. Environmental Modelling \& Software, Volume 25, Issue 12, December, Pages 1754-1768. 


\title{
BC3 WORKING PAPER SERIES
}

\author{
Basque Centre for Climate Change (BC3), Bilbao, Spain
}

The BC3 Working Paper Series is available on the internet at the following address:

http://www.bc3research.org/lits publications.html

http://ideas.repec.org/s/bcc/wpaper.html

BC3 Working Papers available:

2009-04

2009-05

2009-06

2009-07

2009-08

2009-09

2009-10

2009-11

2013-04

2013-05

2013-06

2013-07

Ibon Galarraga, Mikel González-Eguino and Anil Markandya: The Role of Regions in Climate Change Policy

M.C. Gallastegui and Ibon Galarraga: Climate Change and Knowledge Communities

Ramon Arigoni Ortiz and Anil Markandya: Literature Review of Integrated Impact Assessment Models of Climate Change with Emphasis on Damage Functions

Agustin del Prado, Anita Shepherd, Lianhai Wu, Cairistiona Topp, Dominic Moran, Bert Tolkamp and David Chadwick: Modelling the Effect of Climate Change on Environmental Pollution Losses from Dairy Systems in the UK

Ibon Galarraga and Anil Markandya: Climate Change and Its Socioeconomic Importance

Julia Martin-Ortega and Anil Markandya: The Costs of Drought: the Exceptional 2007-2008 Case of Barcelona

Elena Ojea, Ranjan Ghosh, Bharat B. Agrawal and P. K. Joshi: The Costs of Ecosystem Adaptation: Methodology and Estimates for Indian Forests

Luis M. Abadie, José M. Chamorro, Mikel González-Eguino: Optimal Investment in Energy Efficiency under Uncertainty

Sara L. M. Trærup, Ramon Arigoni Ortiz and Anil Markandya: The Health Impacts of Climate Change: A Study of Cholera in Tanzania

Mikel González-Eguino, Ibon Galarraga and Alberto Ansuategi: The Future of Europe's Old Industrial Regions after Copenhagen: the Economic Impact of Climate Policy through the Iron and Steel Industry

Roger Fouquet: Long Run Demand for Energy Services: the Role of Economic and Technological Development

David Heres, Steffen Kallbekken and Ibon Galarraga: Understanding Public Support for Externality-

Correcting Taxes and Subsidies: A Lab Experiment

Ibon Galarraga, Luis María Abadie and Alberto Ansuategi: Economic Efficiency, Environmental Effectiveness and Political Feasibility of Energy Efficiency Rebates: the Case of the Spanish Energy Efficiency "Renove" Plan.

Alexander Golub, Oleg Lugovoy, Anil Markandya, Ramon Arigoni Ortiz and James Wang: Regional IAM: Analysis of Risk-Adjusted Costs and Benefits of Climate Policies

Luis M. Abadie, Ibon Galarraga and Dirk Rübbelke: Evaluation of Two Alternative Carbon Capture and Storage Technologies: A Stochastic Model 